\title{
Do Elections Always Motivate Incumbents? Experimentation vs. Career Concerns
}

Eric Le Borgne and Ben Lockwood 


\title{
IMF Working Paper
}

Research Department

\section{Do Elections Always Motivate Incumbents? Experimentation vs. Career Concerns}

Prepared by Eric Le Borgne and Ben Lockwood ${ }^{1}$

Authorized for distribution by Tamim Bayoumi

March 2003

\begin{abstract}
The views expressed in this Working Paper are those of the author(s) and do not necessarily represent those of the IMF or IMF policy. Working Papers describe research in progress by the author(s) and are published to elicit comments and to further debate.
\end{abstract}

This paper studies a principal-agent model of the relationship between an incumbent officeholder and the electorate, where the officeholder is initially uninformed about her ability. If officeholder effort and ability interact in the "production function" that determines performance in office, then an officeholder has an incentive to experiment-that is, raise effort so that performance becomes a more accurate signal of her ability. Elections reduce the experimentation effect, and the reduction in this effect may more than offset the positive "career-concerns" effect of elections on effort. Moreover, when this occurs, appointment of officeholders may Pareto-dominate elections.

JEL Classification Numbers:D72, D78, H41, J44, J45

Keywords: Career Concern, Elections, Citizen Candidate, Experimentation, Tournaments, Political Business Cycles

Authors' E-Mail Addresses:eleborgne@imf.org; B.Lockwood@warwick.ac.uk

${ }^{1}$ Eric Le Borgne is an Economist in the Economic Modeling Division of the IMF's Research Department; Ben Lockwood is a Professor of Economics at the University of Warwick. 


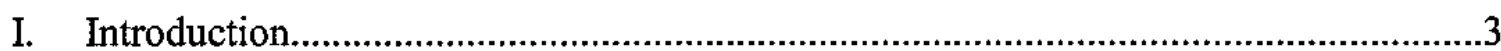

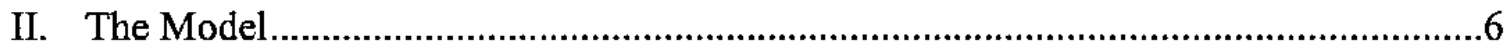

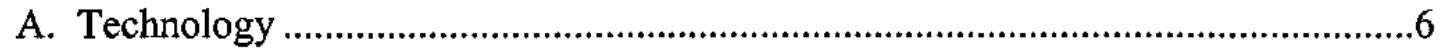

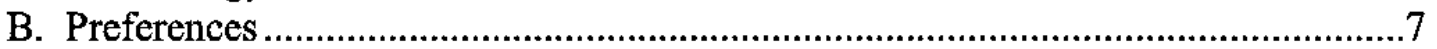

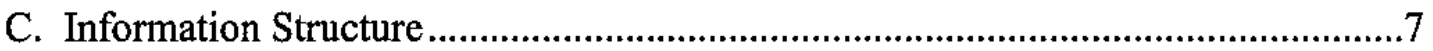

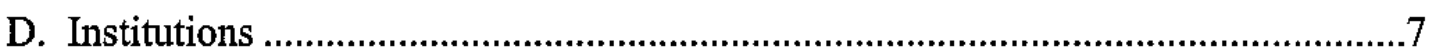

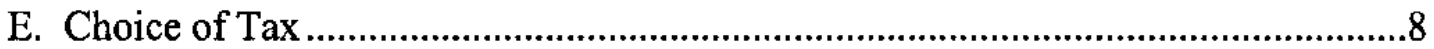

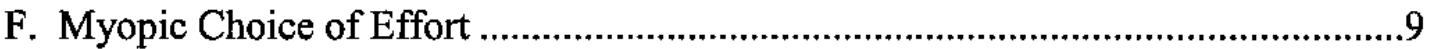

III. Effort Levels Under Appoinment and Democracy ................................................

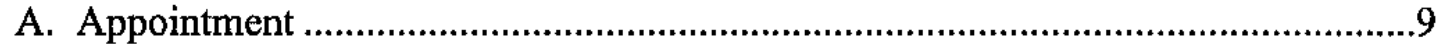

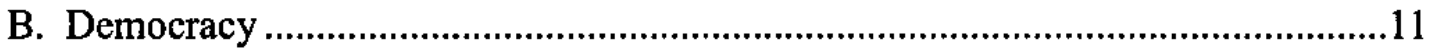

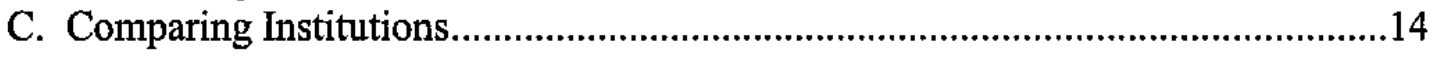

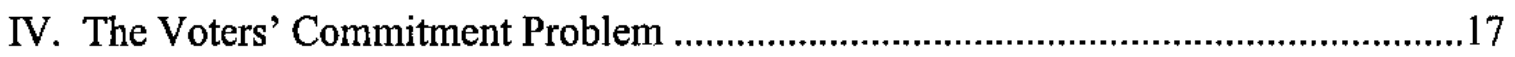

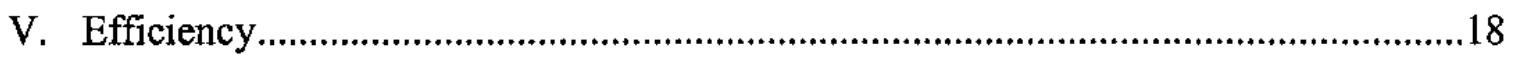

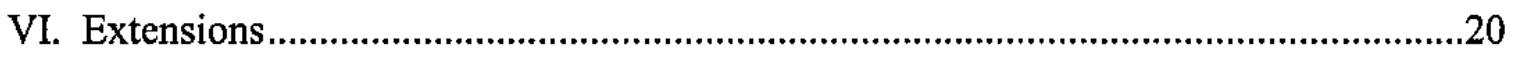

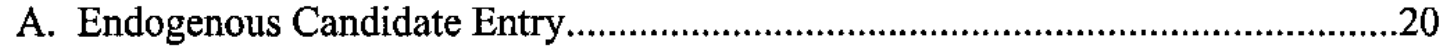

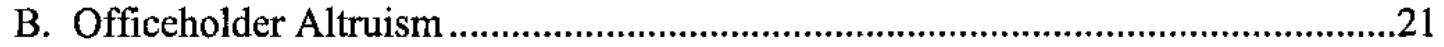

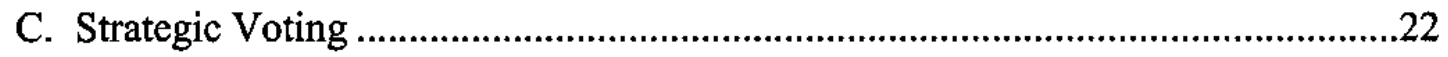

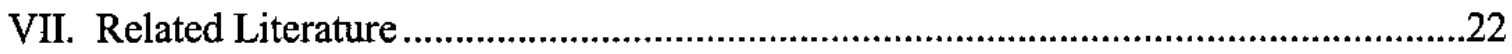

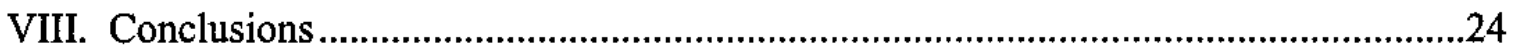

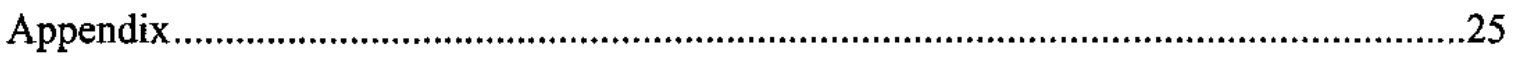

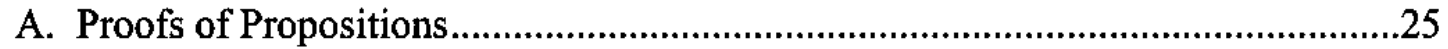

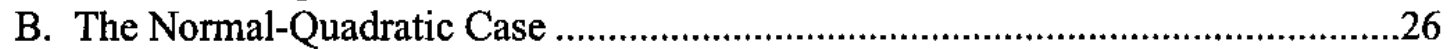

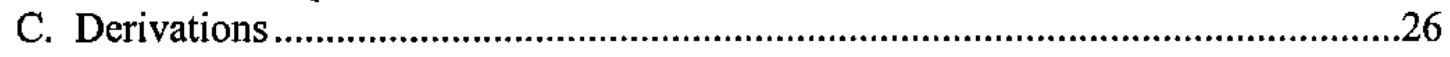

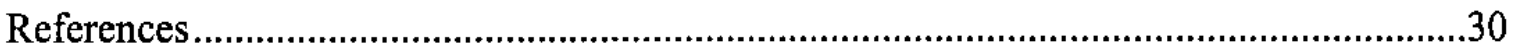

Table

1. Equilibrium Effort Levels $a_{0}^{A}, a_{0}^{D}$ in the Normal-Quadratic Case..............................16 


\section{INTRODUCTION}

In recent years, economists and political scientists have applied principal-agent theory to study the relationship between voters and elected officials. The literature starts from the assumption that there is a moral hazard problem between the elected and the electorate: left to his own devices, the official will pursue his own interests, rather than those of the voters. In some countries, without strong legal or social controls on the activities of those in power, this assumption is quite plausible. The moral hazard problem is modeled formally by supposing that the official can supply unobservable effort (Ferejohn, 1986; Austen-Smith and Banks, 1989; Banks and Sundaram, 1993, 1998) or has the opportunity to divert tax revenue to personal consumption or to special interests without being directly observed (Barro, 1973; Coate and Morris, 1995; Persson and Tabellini, 2000; and Besley and Smart, 2001).

This "political agency" literature modifies standard principal-agent theory in two crucial ways. The first modification is based on the stylized fact that unlike employees, ${ }^{2}$ elected officials cannot typically be offered monetary rewards for their performance on the job: the salaries of political office are usually independent of short-term performance. Second, it is assumed that dismissal (losing elections) is costly for politicians: by losing, they forfeit some rents from office. Under these two conditions, officials can only be motivated (to supply additional effort, to extract less rent) by "career concerns," such as the fear of losing elections. This literature now comprises a variety of models (discussed in more detail in the Conclusions) but with two apparently very robust conclusions; (i) in equilibrium, voters follow a cutoff rule-that is, will only re-elect the incumbent if his observed performance is above a certain critical level; (ii) the cutoff rule always motivates the officeholder (to supply more effort, to extract less rent).

This paper argues that conclusion (ii) is in fact not robust to a simple change in the information structure assumed in the political agency literature. This literature assumes throughout ${ }^{3}$ that potential candidates for office are fully informed about their own abilities, while the electorate are not (asymmetric information). We relax this assumption by supposing that potential candidates for office are no better informed about their own ability in office than the electorate is (symmetric information). This seems empirically just as reasonable an assumption as asymmetric information: reality is surely between these two extreme cases.

With symmetric information, we show that in equilibrium, elections may demotivate: that is,

${ }^{2}$ Within firms, various incentive mechanisms-ranging from promotion and demotion, wage changes, performance contracts (e.g., stock options) - are widely used (see Prendergast, 1999 and Gibbons and Waldam, 1999 for recent surveys).

${ }^{3}$ The only exception is the career-concerns model of Chapter 4.5 of Persson and Tabellini (2000). However, in that model, there is no noise in the production function, so that incumbents can perfectly observe their ability from performance at the end of the first period in office, and, consequently, there is no experimentation effect. See Section VII for more discussion. 
the incumbent will supply less effort than he would without the "discipline" of an election. The intuition is the following. With symmetric information, when the ability and the effort of the officeholder interact positively, the officeholder can learn more about his ability by supplying more effort. We call this the experimentation motive for supplying effort. ${ }^{4}$ However, if he is exposed to the possible future loss of office, his motive to experiment will be reduced. This diminution in the experimentation motive may more than offset the increase in effort induced by the desire to signal competence to the electorate (the career-concerns effect ${ }^{5}$ ). In this event, the agent will supply less effort than he would were he simply permanently appointed to the job. ${ }^{6}$

We also show that the experimentation effect, via its effect on the agent's effort, has other important implications. In Section IV, we study the implications for the nature of the commitment problem of the voters. Since the pioneering work of Ferejohn (1986), it has been recognized that in political-agency models, voters face a commitment problem, in that their inability to precommit to a reelection rule ex ante leads to a welfare loss for them. It is generally believed ${ }^{7}$ that voters would like to commit to a "relatively tough re-election rule that removes even fairly good incumbents from office pour encourager les autres" (Besley and Smart, 2001, p. 8.). In our setting, we are able to clarify under what conditions the voters would like to commit to a tougher cutoff rule than the equilibrium one: a sufficient condition turns out to be the absence of an experimentation motive. By contrast, when the experimentation effect is strong, voters may prefer to precommit-that is, to never expose the incumbent to another election but instead simply appoint him permanently to office.

In Section V, we show that there is also an important relationship between the "efficiency" of equilibrium and the presence of an experimentation motive. Consider a constrained social planner who has the same economic instruments as the officeholder and initially is only as well-informed

\footnotetext{
${ }^{4}$ The experimentation literature initially studied the problem of a monopolist facing an unknown demand curve (Prescott (1972) and Grossman, Kihlstom, and Mirman (1977) are early contributions). Mirman, Samuelson, and Urbano (1993) develop a tractable two-period monopolist game and establish conditions under which experimentation occurs. We make use of their results below. Keller and Rady (1999) surveys the literature. Datta et al. (2002) extend the literature to the case of signal-dependent decision problems.

${ }^{5}$ In our model, the career concerns effect can also be thought of as a tournament between incumbent and challenger (Lazear and Rosen, 1981; Green and Stokey, 1983). Whoever wins office gets "first prize" and whoever loses, "second prize."

${ }^{6}$ One way of interpreting the diminution is as short-termism; the incumbent underinvests in information acquisition, anticipating he will lose power (see also Besley and Coate, 1998 for examples of this type).

${ }^{7} \mathrm{~A}$ result of this kind is proved (in a rather different setting that ours) in Persson and Tabellini (2000), Chapter 4.4, which states that if voters can precommit, they will choose the toughest reelection rule consistent with the incentive constraint of the incumbent.
} 
as the voters and officeholder. We say that equilibrium is constrained efficient ${ }^{8}$ if a constrained social planner cannot make every citizen better off. It turns out that (subject to a uniqueness condition holding) when technology is additive (so there is no experimentation motive), the equilibrium with democracy is constrained efficient, but that this need not be the case with an experimentation motive. In other words, underinvestment in information acquisition can lead to Pareto inefficiency.

Our results also relate to two other literatures. First, our information structure (although not the model of the principal-agent relationship ${ }^{9}$ ) is the same as the career concerns literature of Holmström (1982, 1999), and Dewatripont, Jewitt, and Tirole (1999). This literature-to our knowledge - has not noted the existence of experimentation effects. This is because the existing literature assumes either (i) an additive technology, where information has no value (Holmström, 1982,1999 ) or (ii) one period only, in which case information acquired currently cannot be used in the future (Dewatripont and others, 1999).

Second, our results also have implications for the very general results obtained by Banks and Sundaram (1998) on optimal retention in agency problems. They consider a very general principal-agent model where (i) information about ability is asymmetric - that is, known only by the agent, and (ii) the agent can be controlled only by the (credible) threat of firing. This model includes almost all ${ }^{10}$ existing political-agency models as special cases, as well as having many other applications. In this setting, they show that the ability of the principal to fire the agent unambiguously raises the agent's effort. ${ }^{11}$ As our model (with their information structure) is a special case of theirs, our paper shows that this otherwise very general result is not robust to a change in the information structure.

The rest of the paper is structured as follows. Section II describes the model, and Section III presents the basic results on effort levels. Section IV considers the commitment problem of the voters. Section V is devoted to normative analysis. Section VI discusses some extensions. Section

${ }^{8}$ Of course, due to the underlying agency problem, the equilibrium outcome with democracy will never be first-best efficient, so that the latter is not a very interesting benchmark.

${ }^{9}$ The career-concerns literature focuses on the labor market, not the relationship between the electorate and public officials. Specifically, in the career-concerns literature, the pay of the agent is not exogenous (as in our model) but depends on the employer's belief about the marginal/average product of the agent, and that belief depends, in turn, on past performance.

${ }^{10}$ The exception is Coate and Morris (1995), where asymmetric information is two-dimensional: the incumbent privately observes not only his type but also the type of the public project.

${ }^{11}$ This follows from Proposition 3.2 of their paper, which shows that the lower bound of the support of the random effort in the first period of the agent's life is higher than effort in the second (last) period, when the threat of firing has no force. Given their information structure, second-period effort is the same that would be supplied in the first period if the principal had no power to fire the agent. 
VII discusses related literature. Section VIII concludes.

\section{THE MODEL}

The economy is populated by a set $N$ of citizens with $\# N=n>3$ and evolves over two time periods, $t=0,1$. In each period, every citizen possesses an endowment $\omega$ of a good that can either be privately consumed or transformed into a public good. There is a political office that can be occupied by only one citizen, the "officeholder". In any period $t$, the officeholder levies a lump-sum tax $\tau_{t}$ on the endowments of all citizens, and uses the revenue $n \tau_{t}$ from this tax to produce a public good.

\section{A. Technology}

The amount of the public good produced in any time period, $G_{t}$, depends on both the ability and effort of the officeholder as follows:

$$
G_{t}=\gamma\left(\theta^{i}, a_{t}, \varepsilon_{t}\right) n \tau_{t}
$$

Here, $\theta^{i}$ measures ability of an officeholder $i \in N, a_{t} \in[0, \infty)$ is her effort level in period $t$, and $\varepsilon_{0}, \varepsilon_{1}$ are independently distributed random shocks. We will suppose that the productivity function $\gamma$ takes the following simple form:

$$
\gamma\left(\theta^{i}, a_{t}, \varepsilon_{t}\right)=\exp \left(\mu\left(\theta^{i}+a_{t}\right)+(1-\mu) \theta^{i} a_{t}+\varepsilon_{t}\right)
$$

where $\mu \in[0,1]$. We will say that if $\mu=1$, effort and ability are additive (substitutes) in production; if $\mu>1$, they are non-additive (partly multiplicative/complementary). This specification follows Dewatripont, Jewitt, and Tirole (1999). In either period, the officeholder chooses $\tau_{t}$ and $a_{t}$ before observing $\varepsilon_{t}$.

We assume that each $\theta^{i}$ is a random draw from a distribution that can take two values: $\theta_{H}>\theta_{L}>0$ with probabilities $\pi_{0}, 1-\pi_{0}$ respectively. This draw takes place at the beginning of period zero. So, the $\theta^{i}$ are uncorrelated across citizens. We refer to $H, L$ as the types of the citizens.

We assume that $\varepsilon$ has a continuous distribution with probability density function $f$, cumulative distribution function $F$, and has full support on $\Re$. We assume that $f$ satisfies the Monotone Likelihood Ratio Condition (MLRC) that $f^{\prime}(\varepsilon) / f(\varepsilon)$ is a continuous and decreasing function. We also assume that

A0. For any $a>0$, there exists $\varepsilon^{\prime}, \varepsilon^{\prime \prime}, \varepsilon^{\prime \prime}>\varepsilon^{\prime}$, such that $\frac{f\left(\varepsilon^{\prime}-a\right)}{f\left(\varepsilon^{\prime}\right)}<1<\frac{f\left(\varepsilon^{\prime \prime}-a\right)}{f\left(\varepsilon^{\prime \prime}\right)}$.

It is well-known that a large number of distributions satisfy MLRC (Milgrom, 1981), including the Normal, and it is easy to check that if $\varepsilon$ is Normally distributed, A0 is also satisfied. 


\section{B. Preferences}

Every citizen has preferences over the public good and the tax of the form $H\left(G_{t}\right)+\omega-\tau_{t}$, where $H(G)=\ln G$. So, utility is linear in consumption of the untaxed part of the endowment. If a citizen $i \in N$ is an officeholder in period $t$, he has total payoff $u_{t}=H\left(G_{t}\right)+\omega-\tau_{t}+R-c\left(a_{t}\right)$, where $R$ is an "ego-rent" from being in office (as in Rogoff and Sibert, 1988), deriving from the prestige in managing public affairs, and $c\left(a_{t}\right)$ is the cost of effort. We assume that $c($.$) is strictly$ increasing and strictly convex, and ${ }^{12} c(0)=0, c^{\prime}(0)<1$. If $i \in N$ is the officeholder in period $t$, then $j \neq i$ also has a lexicographically secondary preference for an incumbent with a higher value of the index $i$. This can be thought of as a preference for the "look" of an officeholder, unrelated to his ability to produce public goods as in Rogoff and Sibert (1988) and Rogoff (1990). The role of this last assumption is simply to ensure that the equilibrium selection of candidate(s) for office is non-random, which simplifies the normative analysis.

Note also that the officeholder is selected from the set of citizens, and so receives the same benefit from the public good as any citizen ${ }^{13}$. This plays a crucial role in our analysis, as it implies that the final period officeholder will wish to supply a nonzero amount of effort which, moreover, will depend on her own perceived level of ability when the technology is non-additive, thus giving rise to an experimentation motive.

\section{Information Structure}

Following Holmström (1982/1999) we assume that citizens do not know $\theta=\left(\theta_{1}, \ldots, \theta_{n}\right)$, but all know the joint distribution of $\theta$ (symmetric incomplete information). It is also assumed that the action $a$ is only observable by the incumbent. Because of this, the officeholder cannot be rewarded on the basis of $a$. If he receives a salary, this is modelled as a component of $R$, the "ego-rent". It is also assumed that $G$ is not verifiable, so the officeholder cannot be rewarded on the basis of $G$.

\section{Institutions}

The agent whose task it is to produce the public good (the officeholder) is selected in one of two ways.

\section{Appointment}

At the beginning of period $t=0$, the officeholder is selected from the set of citizens, and is in place for both periods. Given that all citizens are ex ante identical in productivity, by the

${ }^{12}$ The last condition $c^{\prime}(0)<1$ ensures that myopic effort is positive.

${ }^{13}$ This contrasts for example with the models developed in Persson and Tabellini (2000), where politicians do not care directly about public goods. Their assumption simplifies their analysis, but is not really consistent with the view that ultimately, politicians are selected in some way from the citizens. 
secondary "looks" preferences, the efficient choice is selection of $i=n$, and we assume selection is efficient in this sense.

\section{Democracy}

At the beginning of period $t=0$, an officeholder (the incumbent) is selected from the set of citizens. As in the appointment case, we assume that $i=n$ is selected at this stage. This officeholder is in place during period $t=0$ but faces an election at the beginning of period 1 . At this stage, an opponent is selected from the set of remaining citizens. Again, efficient choice of the opponent is $i=n-1$, and we assume that this is the choice. The citizens then vote on the opponent versus the incumbent, and the winner is the officeholder in period $t=1$.

Our modelling of democracy abstracts from the entry decisions of candidates (dealt with in Section 4 below) while allowing the electorate to "fire" bad officeholders. It also is quite close to the modelling of the electoral process in Rogoff and Sibert (1988), and Rogoff (1990).

In both cases, for consistency, we will impose the individual rationality condition that the officeholder prefers to be in office than out.

\section{E. Choice of Tax}

In office at $t$, the officeholder chooses both the tax $\tau_{t}$, and an effort level $a_{t}$. The choice of tax is observable by the other citizens, and thus allows citizens to infer productivity $\gamma_{t}$. Other that this, it does not convey any information about officeholder types, and so it is very convenient to make assumptions sufficient to ensure that it is optimal for the officeholder to tax away all of the endowment of the citizens. Then, given officeholder preferences and (1), an officeholder of given ability and effort level will choose $\tau_{t}$ to maximize $E\left[\ln \gamma_{t} n \tau_{t}\right]-\tau_{t}$, where the expectation is taken with respect to $\varepsilon_{t}$, subject to the constraint that $\tau_{t} \leq \omega$. If the constraint is not binding, the solution to the problem gives the usual Samuelson condition for the choice of $G_{t}$. The constraint will be binding when the expected marginal utility from an increment in $\tau_{t}$ exceeds the cost of unity at $\tau_{t}=\omega$ i.e.

$$
E\left[\frac{1}{\gamma_{t} n \omega} \gamma_{t} n\right]=\frac{1}{\omega}>1
$$

So, we assume $\omega<1$ in what follows, which implies $\tau_{t}=\omega$. Intuitively, the tax base must be small enough relative to the benefit from the public good. Then, from (1), (2), and the choice of $\tau_{t}=\omega$, payoffs over private and public consumption for all citizens are

$$
H\left(G_{t}\right)+\omega-\tau_{t}=\ln G_{t}=g_{t}=\mu\left(\theta^{i}+a_{t}\right)+(1-\mu) \theta^{i} a_{t}+\varepsilon_{t}+\ln (n \omega)
$$

For convenience, we set $\omega=1 / n$ in what follows, so $\ln (n \omega)=0$. 


\section{F. Myopic Choice of Effort}

Consider the choice of effort by an officeholder $i \in N$ who is in power for period $t$ only, and believes he is high-ability with probability $\pi$. This officeholder has objective $E\left[g_{t}+R-c\left(a_{t}\right)\right]$, where the expectation is taken with respect to both $\theta^{i}$ and $\varepsilon_{t}$. So, using (3), noting that $E \varepsilon_{t}=0$, and dropping the time subscripts to lighten notation, we see that the myopic officeholder has objective:

$$
v_{o}(\pi, a)=\pi\left[\mu\left(\theta_{H}+a\right)+(1-\mu) \theta_{H} a\right]+(1-\pi)\left[\mu\left(\theta_{L}+a\right)+(1-\mu) \theta_{L} a\right]+R-c(a)
$$

The first-order condition for the value of $a$ that maximizes (4) is:

$$
\mu+(1-\mu)\left[\pi \theta_{H}+(1-\pi) \theta_{L}\right]-c^{\prime}(a)=0
$$

This solves to give $a^{*}(\pi)$, which we call the myopic optimal action by the officeholder, given a belief that he is competent with probability $\pi$. Also, let $v_{o}(\pi) \equiv v_{o}\left(\pi, a^{*}(\pi)\right)$. For future reference, we can also define

$$
v_{c}(\pi)=\pi\left[\mu\left(\theta_{H}+a^{*}(\pi)\right)+(1-\mu) \theta_{H} a^{*}(\pi)\right]+(1-\pi)\left[\mu\left(\theta_{L}+a^{*}(\pi)\right)+(1-\mu) \theta_{L} a^{*}(\pi)\right]
$$

which is the expected utility of the non-office-holding citizen when both the citizen and the officeholder believe the latter to be competent with probability $\pi$ and the myopic optimal action is chosen.

Some useful properties of $a^{*}$ and the associated value functions $v_{o}, v_{c}$ are the following. First, it is clear from the first-order condition (5) that

$$
\frac{\partial a^{*}}{\partial \pi}=\frac{(1-\mu)\left(\theta_{H}-\theta_{L}\right)}{c^{\prime \prime}\left(a^{*}\right)}
$$

So, $a^{*}$ is independent of $\pi$ if the technology is purely additive and strictly increasing in $\pi$ otherwise. Second, by direct application of the envelope theorem to $v_{o}(\pi)$, we have

$$
v_{o}^{\prime}(\pi)=\frac{\partial v_{o}(\pi, a)}{\partial \pi}=\mu\left(\theta_{H}-\theta_{L}\right)+(1-\mu)\left(\theta_{H}-\theta_{L}\right) a^{*}(\pi)
$$

so $v_{o}$ is strictly increasing in $\pi$. By inspection of (7), $v_{c}$ is also strictly increasing in $\pi$. Moreover, as $R>0$, and by the properties of $c, v_{o}(\pi)>0$, and by inspection, $v_{c}(\pi)>0$.

\section{EFFort LeVels Under APPointment AND Democracy}

\section{A. Appointment}

We solve the appointee's decision problem with the usual dynamic programming approach. In the second period, the appointee faces a myopic problem, so chooses $a_{1}=a^{*}\left(\pi_{1}\right)$ where $\pi_{1}$ is the appointee's posterior belief that he is a high-ability type. The individual rationality condition for 
the appointee is that $v_{o}\left(\pi_{1}\right) \geq 0$ which is always satisfied.

Now, note from (8) above that as long as the technology has a multiplicative component, i.e. $\mu<1$, his second-period payoff is strictly convex in $\pi_{1}$;

$$
v_{o}^{\prime \prime}\left(\pi_{1}\right)=(1-\mu)\left(\theta_{H}-\theta_{L}\right) \frac{\partial a^{*}}{\partial \pi_{1}}>0
$$

This means that information about $\theta$ obtained by Bayesian updating is strictly valuable. Now when updating, the appointee can observe both the $\log ^{14}$ of his own output of the public good in the first period, $g_{0}$, and his action in the first period, $a_{0}$. So, from Bayes' rule, the appointee's posterior belief that he is a high type is

$$
\pi_{1}\left(a_{0}, g_{0}\right)=\operatorname{Pr}\left(\theta=\theta_{H} \mid a_{0}, g_{0}\right)=\frac{\pi_{0}}{\pi_{0}+\left(1-\pi_{0}\right) f_{L}\left(g_{0}, a_{0}\right) / f_{H}\left(g_{0}, a_{0}\right)}
$$

where

$$
f_{k}\left(g_{0}, a_{0}\right) \equiv f\left(g_{0}-(1-\mu) \theta_{k} a_{0}-\mu\left(\theta_{k}+a_{0}\right)\right), k=H, L
$$

Note from (10) and the MLRC that changes in actions are informative, i.e. a change in $a_{0}$ affects the posterior probability that the officeholder is competent, given output $\left(\partial \pi_{1}\left(g_{0}, a_{0}\right) / \partial a_{0} \neq 0\right)$. So, the two well-known ${ }^{15}$ conditions for optimal experimentation are satisfied in our model, i.e. the appointee has an incentive to deviate from the myopic effort level in the first period.

Now we go to the first-period problem for the appointee. Note that for a given value of $a_{0}, g_{0}$ is a random variable with distribution function

$$
\begin{aligned}
H\left(g_{0}, a_{0}\right)= & \pi_{0} F\left(g_{0}-(1-\mu) \theta_{H} a_{0}-\mu\left(\theta_{H}+a_{0}\right)\right)+ \\
& \left(1-\pi_{0}\right) F\left(\left(g_{0}-(1-\mu) \theta_{L} a_{0}-\mu\left(\theta_{L}+a_{0}\right)\right)\right.
\end{aligned}
$$

Consequently, $\pi_{1}\left(g_{0}, a_{0}\right)$ is also a random variable, conditional on $a_{0}$, implying an expected optimized second-period payoff of $E_{g_{0}}\left[v_{o}\left(\pi_{1}\left(a_{0}, g_{0}\right)\right)\right]$. So, the problem for the appointee in the first period is

$$
\max _{a_{0}} v_{o}\left(\pi_{0}, a_{0}\right)+E_{g_{0}}\left[v_{o}\left(\pi_{1}\left(a_{0}, g_{0}\right)\right)\right]
$$

The first-order condition can be written

$$
\left[\mu+(1-\mu)\left(\pi_{0} \theta_{H}+\left(1-\pi_{0}\right) \theta_{L}\right)\right]+\frac{\partial E_{g_{0}}\left[v_{o}\left(\pi_{1}\left(a_{0}, g_{0}\right)\right)\right]}{\partial a_{0}}=c^{\prime}\left(a_{0}\right)
$$

The first term in the square brackets on the left-hand side is the first-period (myopic) gain from a

\footnotetext{
${ }^{14}$ In what follows, we suppose that both the office-holder and voters base all their inferences on $g$, rather than $G$. This is without loss of generality, as $g$ is a strictly increasing function of $G$.

${ }^{15}$ See, for instance, Proposition 1 of Mirman, Samuelson and Urbano (1993).
} 
small increase in effort. The second term on the left-hand side is the marginal experimentation benefit or cost from changing $a_{0}$ from its myopic level $a^{*}\left(\pi_{0}\right)$. Let the value of $a_{0}$ that solves (14) be $a_{0}^{A}$.

The question is now: what sign is the marginal experimentation term? Following the proof of Lemma 2 of Mirman, Samuelson, and Urbano (1993) it is possible to show (see Appendix for details) that

$$
\frac{\partial E_{g_{0}}\left[v_{o}\left(\pi_{1}\left(a_{0}, g_{0}\right)\right)\right]}{\partial a_{0}}=\pi_{0}(1-\mu)\left(\theta_{H}-\theta_{L}\right) \int_{-\infty}^{+\infty} v_{o}^{\prime \prime}\left(1-\pi_{1}\right) \frac{d \pi_{1}}{d g_{0}} f_{H}\left(g_{0}, a_{0}\right) d g_{0}
$$

Now, from (9), $v_{0}^{\prime \prime}>0$ as long as $\mu<1$, and

$$
\frac{d \pi_{1}}{d g_{0}}=\frac{\pi_{0}\left(1-\pi_{0}\right)}{\left[\pi_{0} f_{H}+\left(1-\pi_{0}\right) f_{L}\right]^{2}}\left(f_{L} f_{H}^{\prime}-f_{L}^{\prime} f_{H}\right)>0
$$

from the MLRC. So, we see that

$$
\frac{\partial E_{g_{0}}\left[v_{o}\left(\pi_{1}\left(a_{0}, g_{0}\right)\right)\right]}{\partial a_{0}}>0 \text { iff } \mu<1
$$

i.e. that the experimentation term is strictly positive if and only if the technology is partly multiplicative. So, the following result is immediate from the previous discussion and the strict concavity of $c($.$) :$

Proposition 1. In the second period, the appointee chooses the myopic level of effort $a^{*}\left(\pi_{1}\right)$, conditional on his posterior belief. In the first period, the appointee will choose to experiment by choosing a higher effort than the myopic one, $a_{0}^{A}>a^{*}\left(\pi_{0}\right)$, unless the technology is purely additive $(\mu=1)$, in which case $a_{0}^{A}=a^{*}\left(\pi_{0}\right)$.

\section{B. Democracy}

This case is more complex, as we have a game of incomplete information, where there is both experimentation (unless the technology is additive) and a career concerns effect. We characterize the perfect Bayesian equilibria (PBE) of this game, which turn out to be unique ${ }^{16}$ except that (possibly) the incumbent may choose multiple actions in period 0. Suppose first that the opponent to the incumbent, $j \in N$, is elected at $t=1$. His choice of action is $a_{1}=a^{*}\left(\pi_{0}\right)$, because he has no additional information about his own competence. So, the expected utility to any member $i \neq j$ of the electorate from the opponent is $v_{c}\left(\pi_{0}\right)$.

Now, at the time the electorate votes at $t=1$, every citizen has had the chance to observe, the $\log$ of first-period public good provision. Now, when forming the posterior $\pi_{1}$ given $g_{0}$, citizens rationally deduce that in the first period, the incumbent has taken equilibrium action $a_{0}^{*}$. So, their

${ }^{16}$ Sufficient conditions for uniqueness are derived below. 
posterior probability that the incumbent is competent is

$$
\pi_{1}^{c}\left(g_{0}\right)=\frac{\pi_{0}}{\pi_{0}+\left(1-\pi_{0}\right)\left[f_{L}\left(g_{0}, a_{0}^{*}\right) / f_{H}\left(g_{0}, a_{0}^{*}\right)\right]}
$$

Note that we superscript $\pi_{1}^{c}\left(g_{0}\right)$ to distinguish it from the incumbent's own posterior, which is defined in (10). However, note that in equilibrium, $\pi_{1}^{c}\left(g_{0}\right)=\pi_{1}\left(g_{0}, a_{0}^{*}\right)$. Then the expected utility that citizens can expect from the incumbent is $v_{c}\left(\pi_{1}^{c}\left(g_{0}\right)\right)$.

So, given the tie-breaking rule, all the citizens (apart from possibly the incumbent and the opponent), will vote for the incumbent if and only if $v_{c}\left(\pi_{1}^{c}\left(g_{0}\right)\right) \geq v_{c}\left(\pi_{0}\right)$. As $v_{c}$ is strictly increasing in its argument, this is equivalent to $\pi_{1}^{c}\left(g_{0}\right) \geq \pi_{0}$. From (16), (17), $\pi_{1}^{c}\left(g_{0}\right)$ is strictly increasing in $g_{0}$. Moreover, from this fact and assumption $\mathrm{A} 0$, there exists a unique critical value $\tilde{g}_{0}$ such that $\pi_{1}^{c}\left(\tilde{g}_{0}\right)=\pi_{0}$, with $\pi_{1}>\pi_{0}$ for $g_{0}>\tilde{g}_{0}$, and $\pi_{1}<\pi_{0}$ for $g_{0}<\tilde{g}_{0}$. The conclusion is that all voters (except the incumbent and the opponent) follow the following cutoff rule: vote for the incumbent iff $g_{0} \geq \tilde{g}_{0}$, and for the opponent if $g_{0}<\tilde{g}_{0}$. As there are more than three citizens by assumption, this cutoff rule determines the outcome of the election, i.e. how the incumbent and the opponent vote is irrelevant.

It remains to check that it is individually rational for both the incumbent and the opponent to stand for election, given this cutoff rule. The net gain to winning the election for the incumbent is $v_{o}\left(\pi_{1}^{c}\left(g_{0}\right)\right)-v_{c}\left(\pi_{0}\right)$. Now, the individual rationality condition requires that this gain be positive for $\pi_{1}^{c}\left(g_{0}\right) \geq \pi_{0}$. But from the fact that $v_{o}($.$) is increasing in \pi$, from Section 2.5, we only need that $v_{o}\left(\pi_{0}\right)-v_{c}\left(\pi_{0}\right)=R-c\left(a^{*}\left(\pi_{0}\right)\right) \geq 0$. So, we will assume: ${ }^{17}$

\section{A1. $R>c\left(a^{*}\left(\pi_{0}\right)\right)$}

This simply says that the "net" ego-rent from holding office is positive given prior $\pi_{0}$. Given A1, a similar argument implies that the opponent also wishes to hold office.

So, in view of the preceding discussion, we can write the second-period equilibrium continuation payoff of the incumbent conditional on $g_{0}, a_{0}$ as:

$$
w\left(g_{0}, a_{0}\right)=\left\{\begin{array}{cl}
v_{o}\left(\pi_{1}\left(g_{0}, a_{0}\right)\right), & \text { if } g_{0} \geq \widetilde{g}_{0} \\
v_{c}\left(\pi_{0}\right), & \text { if } g_{0}<\widetilde{g}_{0}
\end{array}\right.
$$

So, the expected second-period continuation payoff of the incumbent, conditional on first-period

${ }^{17}$ The strict inequality in A1 rules out several troublesome borderline cases in the model of Section 6.1 below with endogenous candidate entry. 
effort only, is

$$
\begin{aligned}
E_{g_{0}}\left[w\left(\pi_{1}\left(g_{0}, a_{0}\right)\right)\right]= & v_{c}\left(\pi_{0}\right) H\left(\tilde{g}_{0}, a_{0}\right) \\
& +\int_{\tilde{g}_{0}}^{+\infty} v_{o}\left(\pi_{1}\left(g_{0}, a_{0}\right)\right) h\left(g_{0}, a_{0}\right) d g_{0}
\end{aligned}
$$

where $h\left(g_{0}, a_{0}\right)=\pi_{0} f_{H}+\left(1-\pi_{0}\right) f_{L}$ is the density of $H$ from (12).

Now consider the choice of first-period action for the incumbent, given his continuation payoff (19). This must solve:

$$
u_{0}=\max _{a_{0}}\left\{v_{o}\left(\pi_{0}, a_{0}\right)+E_{g_{0}}\left[w\left(\pi_{1}\left(a_{0}, g_{0}\right)\right)\right]\right\}
$$

The first-order condition can be written as

$$
\mu+(1-\mu)\left(\pi_{0} \theta_{H}+\left(1-\pi_{0}\right) \theta_{L}\right)+\frac{\partial E_{g_{0}}\left[w\left(\pi_{1}\left(a_{0}, g_{0}\right)\right)\right]}{\partial a_{0}}=c^{\prime}\left(a_{0}\right)
$$

After some manipulation, the third term on the left-hand side, evaluated at $a_{0}^{*}$, is given by (see Appendix for details)

$$
\begin{aligned}
\left.\frac{\partial E_{g_{0}}\left[w\left(\pi_{1}\left(a_{0}, g_{0}\right)\right)\right]}{\partial a_{0}}\right|_{a_{0}^{*}}= & \pi_{0}(1-\mu)\left(\theta_{H}-\theta_{L}\right) \int_{\tilde{g}_{0}}^{+\infty} v_{0}^{\prime \prime} \frac{d \pi_{1}}{d g_{0}}\left(1-\pi_{1}\right) f_{H}\left(g_{0}, a_{0}^{*}\right) d g_{0} \\
& +\pi_{0}\left(1-\pi_{0}\right)(1-\mu) v_{0}^{\prime}\left(\pi_{0}\right) f_{H}\left(\widetilde{g}_{0}, a_{0}^{*}\right) \\
& +\left[R-c\left(a^{*}\left(\pi_{0}\right)\right)\right]\left(-\frac{\partial H\left(\tilde{g}_{0}, a_{0}^{*}\right)}{\partial a_{0}}\right)
\end{aligned}
$$

where

$$
-\frac{\partial H\left(\tilde{g}_{0}, a_{0}\right)}{\partial a_{0}}=\pi_{0}\left[\mu+(1-\mu) \theta_{H}\right] f_{H}\left(\tilde{g}_{0}, a_{0}^{*}\right)+\left(1-\pi_{0}\right)\left[\mu+(1-\mu) \theta_{L}\right] f_{L}\left(\tilde{g}_{0}, a_{0}^{*}\right)>0
$$

The first term on the right-hand side represents the "experimentation" effect that we encountered in the appointment case. However, in this case it is clear by inspection that this term is unambiguously smaller than in the appointment case. The intuition is that the democratically elected officeholder only reaps the benefits of experimentation in the event that he is re-elected, which occurs with probability less than one. The second term $\pi_{0}\left(1-\pi_{0}\right)(1-\mu) v_{0}^{\prime}\left(\pi_{0}\right) f_{I I}\left(\widetilde{g}_{0}\right)$, which is positive, is an additional incentive to experiment.

More importantly, the last term in (22) is a new effect which we call the "career concerns" effect, and is the product of two terms. The first, $R-c\left(a^{*}\left(\pi_{0}\right)\right)$ is the net gain, or "prize" to winning the election ${ }^{18}$ when $\pi_{1}=\pi_{0}$. The second term, $-\frac{\partial H}{\partial a_{0}}$, is the increased probability of winning the

${ }^{18}$ This can be related to the tournament literature (Lazear and Rosen, 1981). There, the motivation for effort is to gain the first prize instead of the second prize. Here, the first prize for the incumbent 
"prize" due to a small increment in effort. So, this last term in (22) represents the marginal extra effort that the incumbent officeholder is willing to supply in order to win the election. Note that the last term is always strictly positive by $\mathrm{Al}$.

Let any level of action that solves (21) be denoted $a_{0}^{D}$. As the career concerns effect is always positive, then $a_{0}^{D}>a^{*}\left(\pi_{0}\right)$. Then we can summarize:

Proposition 2. In the second period, the elected official chooses the myopic level of effort $a^{*}\left(\pi_{1}\right)$, conditional on his posterior belief. In the first period, the official will choose a higher effort than the myopic one, $a_{0}^{D}>a^{*}\left(\pi_{0}\right)$, even if the technology is purely additive $(\mu=1)$.

Because $a_{0}^{D}$ is an equilibrium action in a game, we cannot be sure that it inique. In the additive case, from (22), we get

$$
1+\left[\pi_{0} f_{H}\left(\tilde{g}_{0}, a_{0}^{D}\right)+\left(1-\pi_{0}\right) f_{L}\left(\tilde{g}_{0}, a_{0}^{D}\right)\right]\left(R-c\left(a^{*}\right)\right)=c^{\prime}\left(a_{0}^{D}\right)
$$

where $a^{*}$ is the myopic optimal action in period 1 (independent of $\pi_{1}$ ). So, as $c^{\prime \prime}>0$, and $c^{\prime}(0)<1$, a sufficient condition for uniqueness is that left-hand side of (24), viewed as a function of $a_{0}$, is decreasing for all $a_{0} \leq a_{0}^{D}$. But for this, it is sufficient that $f_{H}^{\prime}\left(\tilde{g}_{0}, a_{0}\right), f_{L}^{\prime}\left(\tilde{g}_{0}, a_{0}^{D}\right) \geq 0, a_{0} \leq a_{0}^{D}$, or, more explicitly

$$
f^{\prime}(x) \geq 0, x \leq \tilde{g}_{0}-\theta_{L}-a_{0}^{D}
$$

So, (25) is a sufficient condition for uniqueness in the additive case, and will be useful in what follows. We are also able to show that in the Normal-Quadratic case (i.e. $\varepsilon$ distributed Normally, $c($.$) quadratic), if the technology is additive, the equilibrium action is unique even without (25) -$ see Appendix B.

Moreover, simulations for the Normal-Quadratic case, available on request, show that for a range of parameter values, the equilibrium action is unique even when technology is almost completely multiplicative ( $\mu \simeq 0$ ). So, when comparing institutions in Section 3.3, we will assume that $a_{0}^{D}$ is unique.

\section{Comparing Institutions}

We can now turn to the main topic of the paper, the comparison of effort levels under appointment and democracy. In the final period, conditional on posterior belief about type, the same (inefficiently low) effort level occurs under both institutions. The interesting comparison is

is taking office (with payoff $\left.v_{o}\left(\pi_{0}\right)\right)$ and second prize is losing the election in which case the opponent wins, giving the incumbent $v_{c}\left(\pi_{0}\right)$. Of course, $v_{o}\left(\pi_{0}\right)-v_{c}\left(\pi_{0}\right)=R-c\left(a^{*}\left(\pi_{0}\right)\right)$. Therefore, as in the tournament literature, a policy maker's effort depends on the spread between winning and losing prizes. 
therefore in the first period. Here, it is instructive to compare the incentive to raise the effort level above the myopic optimum in the two cases. The difference between this incentive in the democratic and appointment cases is

$$
\begin{aligned}
\Delta= & {\left[R-c\left(a^{*}\left(\pi_{0}\right)\right)\right]\left(-\frac{\partial H\left(\tilde{g}_{0}, a_{0}\right)}{\partial a_{0}}\right) } \\
& +\left[\begin{array}{c}
\pi_{0}\left(1-\pi_{0}\right)(1-\mu) v_{0}^{\prime}\left(\pi_{0}\right) f_{H}\left(\widetilde{g}_{0}, a_{0}^{*}\right) \\
-\pi_{0}(1-\mu)\left(\theta_{H}-\theta_{L}\right) \int_{-\infty}^{\tilde{g}_{0}} v_{0}^{\prime \prime} \frac{d \pi_{1}}{d g_{0}}\left(1-\pi_{1}\right) f_{H}\left(g_{0}, a_{0}^{*}\right) d g_{0}
\end{array}\right]
\end{aligned}
$$

Again assuming uniqueness of $a_{0}^{D}$, by the convexity of $c\left(\right.$.), $a_{0}^{D}>a_{0}^{A}$ iff $\Delta>0$.

Now, the first term in $\Delta$ is the "career concerns" term, and is positive. The second term in square brackets is the additional incentive for experimentation in the democratic case. Although it is not analytically possible to sign it in general, it is clear that when the technology is (approximately) additive i.e. $\mu \simeq 1$, the second term is zero, and so $\Delta>0$ overall, implying $a_{0}^{D}>a_{0}^{A}$ the conventional result that elections motivate. Illustrative calculations in row 1 of Table 1 show that when the variance of $\varepsilon$ is high, the career concerns effect on effort may be large.

Our main focus of interest is to establish conditions under which elections may demotivate. Inspection of (26) indicates that this is likely to occur when the net ego-rent from office, $R-c\left(a^{*}\left(\pi_{0}\right)\right)$ is close to zero. In this case, there is (approximately) no "career concerns" effect under democracy, so that as long as there is more incentive to experiment with appointment, we will have $\Delta<0$ and hence $a_{0}^{D}<a_{0}^{A}$. For the Normal-quadratic case, simulation results reported in Column 1 of Table 1 below shown that this can easily happen, and the demotivating effect of elections is larger, the more multiplicative the technology is. ${ }^{19}$ Table 1 also shows that it is possible that $\Delta<0$ when $\theta_{H}-\theta_{L}$ is sufficiently large. In this case, information about $\theta$ is valuable, so the appointee's incentive to experiment is strong, and is much diminished by an electoral constraint.

${ }^{19} \mathrm{~A}$ natural way to measure this is in terms of the increase relative to the myopic level of effort $a^{*}\left(\pi_{0}\right)$ induced by either arrangement. When $\mu=0.75,\left(a_{0}^{D}-a^{*}\left(\pi_{0}\right)\right) /\left(a_{0}^{A}-a^{*}\left(\pi_{0}\right)\right) \simeq 1$, but when $\mu=0,\left(a_{0}^{D}-a^{*}\left(\pi_{0}\right)\right) /\left(a_{0}^{A}-a^{*}\left(\pi_{0}\right)\right) \simeq 5 / 8$. 
Table 1. Equilibrium Effort Levels $a_{0}^{A}, a_{0}^{D}$ in the Normal-Quadratic Case

\begin{tabular}{clllll}
\hline$\backslash R-c\left(a^{*}\left(\pi_{0}\right)\right):$ & \multicolumn{1}{c}{$\simeq 0$} & \multicolumn{1}{c}{50} & \multicolumn{1}{c}{100} & $a^{*}\left(\pi_{0}\right)$ \\
\hline$\mu:$ & & & & \\
1.00 & $1.00,1.00$ & $1.00,1.20$ & $1.00,1.40$ & 1.00 \\
0.75 & $4.05,4.03$ & $4.05,4.81$ & $4.05,5.58$ & 4.00 \\
0.50 & $7.69,7.41$ & $7.69,8.61$ & $7.69,9.71$ & 7.00 \\
0.25 & $12.08,11.22$ & $12.08,12.19$ & $12.08,13.00$ & 10.00 \\
0.00 & $15.00,14.25$ & $15.00,14.69$ & $15.00,15.07$ & 13.00 \\
$\theta_{H}-\theta_{L}:$ & & & & \\
0.5 & $1.1250,1.1253$ & $1.125,1.35$ & $1.1250,1.57$ & 1.1250 \\
10 & $3.51,3.52$ & $3.51,4.21$ & $3.51,4.91$ & 3.50 \\
20 & $6.34,6.21$ & $6.34,7.33$ & $6.34,8.39$ & 6.00 \\
50 & $15.05,14.43$ & $15.05,14.75$ & $15.05,15.03$ & 13.5 \\
\hline
\end{tabular}

When $\mu$ is variable, other parameters are: $\pi_{0}=0.5, \theta_{H}=25, \theta_{L}=1, \sigma=100$. When $\theta_{H}-\theta_{L}$ is variable, other parameters are: $\pi_{0}=0.5, \mu=0.5, \sigma=100$.

Next, consider the expected probability (taken with respect to $\theta_{1}, \ldots, \theta_{n}$ ) that the officeholder is a high-type, under any institutional arrangement. The expected probability that the officeholder in either period is high-type under appointment is $\pi_{0}$, as is the probability that the officeholder is high-type in the first period, with democracy. In the second period, the expected probability that the officeholder is a high-type is

$$
\operatorname{Pr}\left(\theta^{i}=\theta_{H} \mid g_{0} \geq \widetilde{g}_{0}\right)\left(1-H\left(\widetilde{g}_{0}, a_{0}^{*}\right)\right)+\pi_{0} H\left(\widetilde{g}_{0}, a_{0}^{*}\right)=\hat{\pi}_{1}>\pi_{0}
$$

So, we can summarize the discussion as follows:

Proposition 3. The same (myopic) level of effort is chosen in all cases in the second period. In the first period, $a_{0}^{D}>a_{0}^{A}$, if the technology is additive (in which case there is no motive for cxperimentation), but it is possible that $a_{0}^{D}<a_{0}^{A}$ if the "prize" for office $R-c\left(a^{*}\left(\pi_{0}\right)\right)$ is approximately zero or $\theta_{H}-\theta_{L}$ is sufficiently large.

With appointment, a high-ability type is selected in both periods with expected probability $\pi_{0}<1$. With democracy, a high-ability type is selected in the first period with probability $\pi_{0}$ and in the second with probability $\hat{\pi}_{1}>\pi_{0}$.

This raises the possibility that democracy need not be more "efficient" than appointment, as the former, while undoubtedly raising the average quality of the second-period officeholder, may lower effort (relative to appointment). This is investigated further in Section 5 below. 


\section{The Voters' Commitment Problem}

Since the pioneering work of Ferejohn (1986), it has been recognized that in political agency models, voters face a commitment problem, in that their inability to precommit to a re-election rule ex ante leads to a welfare loss for them. In a world with pure moral hazard (i.e. without different ability types) this takes an extreme form: as Banks and Sundaram (1998) show, in equilibrium, the agent will always choose the myopic level of effort (Proposition 3.5) whereas if the principal could precommit, he would choose a tougher retention rule than the equilibrium one.

Here, we show that with an experimentation motive, a tougher retention rule than the equilibrium one need not be optimal. Define the "principal" to be the set of citizens $V=\{1, \ldots, n-2\}$ who cannot expect to hold office. Suppose that this group can precommit to an arbitrary cutoff $\gamma$ so that $n$ is not re-elected iff $g_{0}<\gamma$. Assume that technology is additive, i.e. $\mu=1$. Also, let $a_{0}(\gamma)$ be the officeholder's first-period action given the cutoff. So, $a_{0}(\gamma)$ solves (24) with $\gamma$ replacing $\widetilde{g}_{0}$. Now, the ex ante expected utility over periods 0,1 for any $i \in V$, conditional on a cutoff $\gamma$ is :

$$
v_{i}(\gamma)=\bar{\theta}+a_{0}(\gamma)+\int_{\gamma}^{\infty} v_{c}\left(\pi_{1}\left(a_{0}(\gamma), g_{0}\right)\right) h\left(g_{0}, a_{0}(\gamma)\right) d g_{0}+H\left(\gamma, a_{0}(\gamma)\right) v_{c}\left(\pi_{0}\right)
$$

where $\bar{\theta}=\pi_{0} \theta_{H}+\left(1-\pi_{0}\right) \theta_{L}$. Here, the first term $\bar{\theta}+a_{0}\langle\gamma)$ is the first-period payoff, and the remaining terms give the second-period payoff, recalling that the incumbent $n$ will be replaced with $n-1$ if $g_{0}<\gamma$. Let the value of $\gamma$ that maximizes (27) be $\gamma^{*}:$ this is the cutoff-value that the electorate would choose ex ante if it could precommit. Then we have:

Proposition 4. If technology is additive, and (25) holds, then $\gamma^{*}>\widetilde{g}_{0}$, i.e. the ex ante optimal cutoff rule is tougher than the ex post optimal cutoff rule.

This result says that with an additive technology, the electorate always wish to commit to a tougher dismissal rule than the one that they choose in equilibrium. The intuition is simple: a small increase in $\gamma$, starting at $\widetilde{g}_{0}$, will have two effects on voter welfare. First, it will increase first period effort $a_{0}$, as $a_{0}$ is increasing in $\gamma$ at $\gamma=\widetilde{g}_{0}$ (see the proof of Proposition 4 for details). Second, it will change the probability that a high-quality candidate is chosen for office in the second period. Besley and Smart (2001) call these effects the incentive and selection effects respectively. The key point is that starting at $\widetilde{g}_{0}$, the selection effect is second-order, as the equilibrium cutoff rule $\widetilde{g}_{0}$ is defined by the condition that selection is optimal, i.e. the candidate believed to be highest ability is selected. On the other hand, the incentive effect is first-order. So, the voters can always gain by increasing $\gamma$ slightly from $\widetilde{g}_{0}$.

If, on the other hand, technology is non-additive, this argument clearly does not hold in the case when first-period effort $a_{0}$ is decreasing in $\gamma$. Indeed, in the example in the following Section, it is 
shown that $i \in V$ would be better off if they could precommit to never voting the incumbent out of office - a very weak cutoff rule. The intuition is of course, that with a (strongly) non-additive technology, the experimentation effect may dominate the career concerns effect, making the overall incentive effect (in Besley and Smart's terminology) strongly negative.

\section{EFFICIENCY}

In this section, we address the question of whether the equilibrium outcome under our main institution of interest, democracy, is Pareto-efficient relative to some benchmark. An outcome here is defined as (i) a choice of officeholder in each period; (ii) a level of action by the officeholder in each period, conditional on his information about his type. With democracy, outcomes (i) and (ii) are described by Propositions 1 and 2. So, we are following Wittman (1989) and Besley and Coate (1998), in studying efficiency of democracy in the Pareto sense, rather than relative to some arbitrary social welfare function (e.g., Benthamite) for a social planner. ${ }^{20}$

One possible benchmark is what could be achieved by a social planner with complete information (i.e. knowing $\theta_{1}, \ldots, \theta_{n}$ ) who can choose the identity and effort of the officeholder, and a full set of economic instruments (i.e. can make unrestricted transfers of some numéraire good between citizens). Say that equilibrium is unconstrained efficient if this social planner cannot choose a feasible outcome that makes every citizen better off. We have assumed that citizen utilities are linear in the numéraire good. So, as the social planner can make unrestricted transfers between agents, democracy is unconstrained efficient if and only if it selects the same conditional actions in each period, and the same choice of officeholder, as does the social planner ${ }^{21}$. It is clear that democracy cannot be unconstrained efficient. First, clearly, the social planner will always select a high ability citizen for office, whereas in equilibrium, from Proposition 3, this occurs with probability less than one. Also, the social planner will choose a (higher) level of effort for the officeholder which internalizes the externality arising from the fact that performance in office is a public good. ${ }^{22}$

The weakness of the unconstrained efficiency benchmark is of course that the social planner is given superior information and more economic instruments than the officeholder. Consider now

\footnotetext{
${ }^{20}$ All citizens have identical preferences over outcomes in any period (a choice of officeholder and an effort level for this officeholder). However, as the "good" of office is indivisible, and effort is costly, any outcome must be horizontally inequitable, and so the social planner faces the problem of preference aggregation.
}

${ }^{21}$ We can ignore the choice of taxes in this discussion as by assumption, the social planner will always wish to set the maximal $\operatorname{tax} \tau=\omega$.

${ }^{22}$ Specifically, as there are $n$ citizens, each of whom gets utility $g$ from a level of the public good $G$, the social planner will choose officeholder effort $a$ to maximize the expected value of $n g$ minus $c(a)$, conditional on a high-type being in office, i.e. it solves $n\left(\mu+(1-\mu) \theta_{H}\right)=c^{\prime}(a)$. 
a constrained social planner who has the same economic instruments as the officeholder (i.e. no ability to redistribute the numéraire good), and has the same information as the citizens (i.e. only knows the distribution of $\theta$ initially). Say that democracy is constrained efficient if this social planner cannot choose a feasible outcome that makes every citizen better off. Constrained efficiency is a much weaker test for any institution.

It is easy to see that the only feasible actions for the constrained social planner are (i) selection of an officeholder in the first period based only on public information; (ii) replacement of the initial officeholder by another citizen if the only publicly observable indicator of the incumbent's performance, $g_{0}$, falls into some "unacceptable" set $U$. So, the social planner can do no better than to select $n$ as the initial officeholder, and choose $n-1$ in the event that $g_{0} \in U$. Moreover, from the assumption of the MLRC, the social planner can do no better than to set $U=\left\{g_{0} \mid g_{0}<g_{0}^{*}\right\}$, i.e. follow a cutoff rule. Obviously, if $g^{*}=-\infty$, this is simply appointment, and if $g_{0}^{*}=\widetilde{g}_{0}$, democracy.

Our first result is that without an experimentation motive, democracy is weakly efficient:

Proposition 5. Democracy is weakly efficient (i.e. $g_{0}^{*}=\tilde{g}_{0}$ ) if the technology is additive $(\mu=1)$ and in addition (i) the sufficient condition (25) for uniqueness of $a_{0}^{D}$ holds; (ii) $R>c\left(a^{*}\right)+\pi_{0}\left(\theta_{H}-\theta_{L}\right)$.

The key idea behind the proof of this result is that with additive technology, there is never unanimity about changing $g_{0}^{*}$ from $\tilde{g}_{0}$; the initial officeholder will always prefer a cutoff as low as possible (i.e. $g_{0}^{*}=-\infty$ ), effectively making him an appointee, but by Proposition 4 above, all citizens who never hold office always prefer (ex ante) a $g_{0}^{*}$ higher than $\widetilde{g}_{0}$, in order to motivate the initial officeholder to supply more effort. Note finally that the condition $R>c\left(a^{*}\right)+\pi_{0}\left(\theta_{H}-\theta_{L}\right)$ is a strengthening of $\mathrm{Al}$.

However, in the presence of an experimentation motive $(\mu<1)$, democracy may not even be constrained efficient. The reason is that the argument of the previous paragraph breaks down when the technology becomes multiplicative, as then (due to the experimentation effect) the initial officeholder may be motivated ${ }^{23}$ by lowering the cutoff $g_{0}^{*}$, as then he captures more of the gains from experimenting. In turn, this makes voters better off. So then, everybody may gain from a lowering of $g_{0}^{*}$. The following example shows that this may indeed be the case.

\section{Example 1.}

Recall that the incumbent is $n$ and the opponent $n-1$. So, equilibrium payoffs under democracy,

${ }^{23}$ This also requires that the career concerns effect will be small, i.e. that the "prize" for winning the election $\left(R-c\left(a^{*}\left(\pi_{0}\right)\right)\right)$ is approximately zero. 
allowing $\mu \neq 1$, are:

$$
\begin{aligned}
v_{n}^{D}= & \mu\left(\bar{\theta}+a_{0}^{D}\right)+(1-\mu) \bar{\theta} a_{0}^{D}+R-c\left(a_{0}^{D}\right)+\int_{g_{0}}^{\infty}\left[v_{o}\left(\pi_{1}\left(a_{0}^{D}, g_{0}\right)\right) h\left(a_{0}^{D}, g_{0}\right) d g_{0}+\right. \\
& H\left(\widetilde{g}_{0}, a_{0}\left(\widetilde{g}_{0}\right)\right) v_{c}\left(\pi_{0}\right) \\
v_{n-1}^{D}= & \mu\left(\bar{\theta}+a_{0}^{D}\right)+(1-\mu) \bar{\theta} a_{0}^{D}+\int_{g_{0}}^{\infty} v_{c}\left(\pi_{1}\left(a_{0}\left(\widetilde{g}_{0}\right), g_{0}\right)\right) h\left(g_{0}, a_{0}\left(\widetilde{g}_{0}\right)\right) d g_{0}+H\left(\widetilde{g}_{0}, a_{0}\left(\widetilde{g}_{0}\right)\right) v_{o}\left(\pi_{0}\right) \\
v_{j}^{D}= & \mu\left(\bar{\theta}+a_{0}^{D}\right)+(1-\mu) \bar{\theta} a_{0}^{D}+\int_{g_{0}}^{\infty} v_{c}\left(\pi_{1}\left(a_{0}\left(\widetilde{g}_{0}\right), g_{0}\right)\right) h\left(g_{0}, a_{0}\left(\widetilde{g}_{0}\right)\right) d g_{0}+H\left(\widetilde{g}_{0}, a_{0}\left(\widetilde{g}_{0}\right)\right) v_{c}\left(\pi_{0}\right), \\
j< & n-1
\end{aligned}
$$

Also, under appointment of citizen $n$, the expected utilities are

$$
\begin{aligned}
v_{n}^{A} & =\mu\left(\bar{\theta}+a_{0}^{A}\right)+(1-\mu) \bar{\theta} a_{0}^{A}+R-c\left(a_{0}^{A}\right)+\int_{-\infty}^{\infty}\left[v_{o}\left(\pi_{1}\left(a_{0}^{A}, g_{0}\right)\right) h\left(a_{0}^{A}, g_{0}\right) d g_{0}\right. \\
v_{j}^{A} & =\mu\left(\bar{\theta}+a_{0}^{A}\right)+(1-\mu) \bar{\theta} a_{0}^{A}+\int_{-\infty}^{\infty}\left[v_{o}\left(\pi_{1}\left(a_{0}^{A}, g_{0}\right)\right) h\left(a_{0}^{A}, g_{0}\right) d g_{0}, j<n\right.
\end{aligned}
$$

We now show that an example can be chosen where appointment strictly Pareto-dominates democracy. The example is the following. First, $\varepsilon$ is Normal, with mean zero and $\sigma=50$, and $c(a)=a^{2} / 2$, and other parameters are: $\mu=0.5, \pi_{0}=0.55, R=40, \theta_{H}=25, \theta_{L}=1, \delta=1$. In this case, equilibrium payoffs can be calculated using the above formulae as:

$$
\begin{aligned}
v_{n}^{A} & =158.5, v_{j}^{A}=152.0, j<n \\
v_{n}^{D} & =150.1, v_{n-1}^{D}=149.5, v_{j}^{D}=144.4, j \neq n, n-1
\end{aligned}
$$

So, we see that $v_{i}^{D}<v_{i}^{A}, i \in N$ : that is, appointment Pareto-dominates democracy.

\section{EXTENSIONS}

\section{A. Endogenous Candidate Entry}

Our model of the electoral process is incomplete in the sense that endogenous candidate entry is not modeled. In an earlier, longer version of this paper, (Le Borgne and Lockwood, 2000), we allow for both entry and voting to be modelled in a complete way without any ad hoc assumptions. The set-up is as follows. There is an election at the beginning of each of the two time periods. The first stage of the election process is candidate entry. Any citizen can stand for election in either of the two periods, at a cost of $\delta>0$. The second stage is plurality voting over the set of candidates. ${ }^{24}$ This describes a multi-stage game between the $n$ citizens.

\footnotetext{
${ }^{24}$ In the event of a tie (i.e. two or more candidates with equal numbers of votes) we adopt the standard tie-breaking rule that every candidate with the most votes is chosen with equal probability. In the event that nobody stands for election, a default option is selected by the constitution, which is that no public good is provided.
} 
In Le Borgne and Lockwood (2000), the (perfect Bayesian) equilibria of this model are characterized. Let $a_{0}^{D E N}$ be the solution to (21) above, but where $R$ is replaced by $R-\delta$. Again, we will assume that $a_{0}^{D E N}$ is unique, which as argued above, is a weak restriction in the Normal-Quadratic case. The interpretation of $a_{0}^{D E N}$ is that it is the first-period effort chosen by an incumbent with endogenous entry. Then it is clear that $a_{0}^{D E N}<a_{0}^{D}$, as in the endogenous entry case, the "prize" for winning the election is reduced by the amount of the entry cost (and also $\left.a^{*}\left(\pi_{0}\right)<a_{0}^{D E N}\right)$. Finally, we make the following assumption, which ensures that candidate entry costs are low enough so that some agent will stand for election, and high enough to deter all agents from standing for election:

A2. $\frac{1}{n} v_{o}\left(\pi_{0}\right)<\delta<v_{o}\left(\pi_{0}\right)$

We then have the following result, proved in Le Borgne and Lockwood (2000):

Proposition 6. Assume A0,A2. Then, with symmetric incomplete information, there is a unique equilibrium with the following structure. In period 0 , only $i=n$ stands for election and is elected. He chooses action $a_{0}^{D E N}$. In period 1 , if $g_{0} \geq \widetilde{g}_{0}$, only $i=n$ stands for election and is elected. He chooses action $a^{*}\left(\pi_{1}\left(g_{0}, a_{0}^{*}\right)\right)$. If $g_{0}<\widetilde{g}_{0}$, only $i=n-1$ stands for election and is elected. He chooses action is $a^{*}\left(\pi_{0}\right)$.

The intuition for the entry decisions in equilibrium is that given that citizens do not know their own types, no citizen runs for election on the basis of her superior ability in the first period. Only the citizen with the best "look" stands for election and is elected: non-economic variables decide which citizen becomes candidate and officeholder in the first period. In the second period, the incumbent is re-elected if his track record is sufficiently good, and anticipating this, he stands. On the other hand, if his track record is weak, he does not bother to stand (rationally anticipating defeat if he does), thus allowing the remaining citizen with the best "look" to stand and win. Note, however, that once in office in the first period, the incumbent's choice of effort is exactly the same (modulo the fact that $\delta$ reduces the ego-rent) as in the baseline case of democracy. So, our results are robust to the introduction of endogenous candidate entry. ${ }^{25}$

\section{B. Officeholder Altruism}

The assumptions of the model generate a very strong form of under-provision of effort; as effort is noncontractible, the officeholder only has $1 / n$ of the correct incentive to provide effort. Consequently, (at least for large $n$ ), the higher equilibrium effort, the more efficient the effort is. This strong result can be refined by the (admittedly, ad hoc) device of supposing that the position

\footnotetext{
${ }^{25}$ As shown in a companion paper (Le Borgne and Lockwood, 2002) this need not be the case under an asymmetric information structure - as is commonly assumed in the literature.
} 
of office has some psychological impact on the officeholder, making him more altruistic. ${ }^{26}$ This can be modelled by supposing that the ego-rent from office is $R+r g_{t}$ where $r>0$, so the ego-rent interacts positively with the amount of public good provided. ${ }^{27}$ If $r>0$, the positive analysis of the paper is qualitatively unchanged, but equilibrium effort will be higher.

\section{Strategic Voting}

Our analysis has assumed that voters vote sincerely (i.e. for their most preferred candidate) at each election, no matter what the candidate set is. However, it is well known ${ }^{28}$ that when there are three or more candidates, voting sincerely might not be the only Nash equilibrium strategy (see Besley and Coate, 1997; or Dhillon and Lockwood, 2000). For example, in our model, it is a Nash equilibrium for all voters to vote for the candidate with the lowest index (i.e. looks characteristic). This is because no single voter can change the outcome by deviating, and so it is a weak best response to vote this way. However, as looks are uncorrelated with competence, this would not change the equilibrium outcome in any economically relevant way.

\section{RELATED LITERATURE}

In a classic article, ${ }^{29}$ Ferejohn (1986) proposed a simple and elegant moral hazard model of electoral control of officeholders. In equilibrium, voters follow a cutoff rule by voting for the incumbent only if his observed performance does not fall below a certain level, and the candidate chooses effort so that performance remains just at the cutoff. So, officeholder effort is higher than it would be without elections (there is electoral control of the incumbent). As Ferejohn himself recognized (see p10 of his paper) his analysis relies ${ }^{30}$ on the assumption that official may stay in office forever (no term limits). With term limits, incumbents can never be induced to supply more than their myopic level of effort in the final period, and an "unraveling" argument then shows that

${ }^{26}$ Holmström and Milgrom (1991) have such a type of assumption in their multitask agency model: they assume that not all work is unpleasant for an agent so that even without explicit incentives, the agent will supply effort on some tasks.

${ }^{27}$ Of course, $r>0$ could also model a public duty/altruistic motive for the office-holder, capturing the fact that holders of public office may feel some obligation towards the citizens they represent, quite independently from the discipline that elections impose.

${ }^{28}$ There is also much empirical evidence that it occurs in single-seat elections by plurality rule (Cox, 1997).

${ }^{29}$ Barro (1973) was the first to explicitly model electoral control of politicians. However, in his model, the actions of officeholders were always observable, and so if officeholders are infinitely lived, they can always be induced to take efficient actions, if discounting is sufficiently low (by a simple folk theorem argument).

${ }^{30}$ With term limits, Ferejohn's model can only exhibit electoral control in equilibrium if voters can precommit to a cutoff rule, a rather unattractive assumption. 
in equilibrium, incumbents can then never be induced to supply more than their myopic level of effort in the any period of office. ${ }^{31}$

More recently, Banks and Sundaram $(1993,1998)$ have shown that even with finite term limits, there can be electoral control of the incumbent in equilibrium if there is also an adverse selection ingredient to the model, namely, some ability parameter of the potential officeholder that is initially unobservable to the electorate. In this case, it is no longer ex post optimal to "fire" the incumbent in his last term of office if he has revealed himself to be of high enough quality. Indeed, under some very weak regularity conditions, the threat of (electoral) ${ }^{32}$ dismissal induces agents of all types to supply more effort that they would otherwise in their first term of office ${ }^{33}$ (Proposition 3.3). Other models with the same basic structure as Banks and Sundaram (1998) include Coate and Morris (1995), and Besley and Smart (2001).

All these models, however, make the assumption of asymmetric information, i.e. the incumbent is informed about his ability type. By contrast, Persson and Tabellini (2000, Chapter 4.5), have a two-period model with both adverse selection and moral hazard, where, as in this paper, initially the incumbent does not know his type. ${ }^{34}$ In their model, given an incumbent with ability $\theta$, the technology for supplying the public good is

$$
g_{t}=\theta\left(\tau-r_{t}\right)
$$

where $g_{t}$ is output of the public good, $\tau$ is exogenous tax revenue, and $r_{t}$ are rents misappropriated from tax revenues. So, incumbents transform tax revenues net of rents into public goods. Voters care only about the level of public good provision, and the officeholder in period $t$ has payoff $R+r_{t}$, where $R$ is an ego-rent, as in our model.

Although Persson and Tabellini model rents in monetary terms, one (formally very similar) way of interpreting rent is to assume that it is the degree to which the official "slacks" from the first-best level of effort defined in footnote 23 i.e. $r=a^{* *}-a$. In that case, we can write our production function, assuming $\mu=1$ as

$$
g_{t}=\theta\left(a^{* *}-r_{t}\right)+\varepsilon_{t}
$$

\footnotetext{
${ }^{31}$ For a formal statement of this result, see Banks and Sundaram (1998), Proposition 3.5.

${ }^{32}$ Banks and Sundaram have a general model where the principal can only control the agent by dismissing him. This has an electoral interpretation, amongst others.

${ }^{33}$ See Besley and Case (1995) for an empirical test of the effects of term limits on the behavior of U.S. state governors.

${ }^{34}$ Biglaiser and Mezzetti (1997) have a paper where in the first period, the incumbent chooses an observable discrete project, but where the value of the project depends on the incumbent's ability (initially unknown to everybody) and a random shock. The paper focuses on the issue of whether undertaking the project is a good or bad signal to the electorate about the incumbent's ability.
} 
which is of course formally identical to (28) except we now have a random productivity shock. Also, note that the payoffs to the officeholder in our model can be written $R+g_{t}-c\left(a^{* *}-r_{t}\right)$. So, the payoffs in Persson and Tabellini correspond to the special case where $c($.$) is additive and$ the incumbent does not care about the public good. ${ }^{35}$

To conclude, the Persson and Tabellini career concerns model can be thought of as a "special case" of ours, ${ }^{36}$ and moreover, one in which the experimentation effect is ruled out by construction. Of course, the merit of their model is that it is very simple and easily analyzed, and so it very well-suited to an analysis of the way career concerns are affected by electoral rules (Persson and Tabellini (2000), chapter 9.1). This would be much more difficult with a model such as ours.

\section{Conclusions}

We have shown that when the informational assumptions of the political-agency literature are changed (by supposing that candidates for office are less than certain about their abilities), an experimentation motive for choice of effort comes into play. This motive is weakened by elections, and so if the experimentation motive is strong enough, elections may demotivate officeholders (relative to those who gain office through appointment). The intuition behind our results is, however, more general and applies to other labor markets: as long as the agent has some positive probability of being "fired" by the principal, that the model is dynamic and that talent and effort are complementary, then both career concerns and experimentation will be present. Extension of the analysis of this paper to other labor markets is a topic for further work.

${ }^{35}$ This last fact creates the modeling problem that in the final period, the incumbent will supply no effort, i.e. extract maximum rent, whatever his type, implying that voters do not care about the types of the elected officials. Persson and Tabellini deal with this in a relatively ad hoc way by imposing an upper bound on the amount of rent that can be extracted.

${ }^{36}$ Mathematically, it is not literally a special case, as in their model, $\theta$ is continuously distributed. 
APPENDIX I

\section{Proofs of Propositions and Derivations}

\section{A. Proofs of Propositions}

Proof of Proposition 4. First, totally differentiating (24), we get

$$
\begin{aligned}
a_{0}^{\prime}(\gamma) & =\frac{A}{c^{\prime \prime}\left(a_{0}(\gamma)\right)+A} \\
A & =\left[\pi_{0} f_{H}^{\prime}\left(\gamma, a_{0}(\gamma)\right)+\left(1-\pi_{0}\right) f_{L}^{\prime}\left(\gamma, a_{0}(\gamma)\right)\right]\left(R-c\left(a^{*}\right)\right)
\end{aligned}
$$

Also, $c^{\prime \prime}>0$, and as (25) holds we have $A \geq 0, \gamma \leq \widetilde{g}_{0}$. So, from (A-1) we have

$$
0 \leq a_{0}^{\prime}(\gamma)<1, \gamma \leq \widetilde{g}_{0}
$$

Now differentiating (27), and noting that with an additive technology, $H\left(\gamma, a_{0}(\gamma)\right)=$ $H\left(\gamma-a_{0}(\gamma)\right)$, we have;

$$
v_{j}^{\prime}(\gamma)=\frac{\partial v_{j}}{\partial a_{0}} a_{0}^{\prime}(\gamma)+h\left(\gamma, a_{0}(\gamma)\right)\left[v_{c}\left(\pi_{0}\right)-v_{c}\left(\pi_{1}\left(a_{0}(\gamma), \gamma\right)\right)\right], j<n-1
$$

Now, note from (10) that with an additive technology, $\pi_{1}\left(a_{0}(\gamma), \gamma\right) \equiv \pi_{1}\left(\gamma-a_{0}(\gamma)\right)$, with $\pi_{1}^{\prime}()>$.0 by the MLRC. So, from this fact and the fact from (A-2) that $\gamma-a_{0}(\gamma)$ is increasing in $\gamma$, from (A-3), and the fact that $v_{c}$ is increasing in $\pi_{1}$, we have

$$
v_{c}\left(\pi_{1}\left(a_{0}(\gamma), \gamma\right)\right) \leq v_{c}\left(\pi_{1}\left(a_{0}\left(\widetilde{g}_{0}\right), \widetilde{g}_{0}\right)\right), \gamma \leq \widetilde{g}_{0}
$$

Also:

$$
v_{c}\left(\pi_{0}\right)=v_{c}\left(\pi_{1}\left(a_{0}\left(\tilde{g}_{0}\right), \widetilde{g}_{0}\right)\right)
$$

where we have used the definition of $\widetilde{g}_{0}$ that $\pi_{0}=\pi_{1}\left(a_{0}\left(\tilde{g}_{0}\right), \widetilde{g}_{0}\right)$ Therefore, from (A-3), (A-5), we see that

$$
v_{j}^{\prime}(\gamma) \geq \frac{\partial v_{j}}{\partial a_{0}} a_{0}^{\prime}(\gamma), \gamma \leq \widetilde{g}_{0}, j<n-1
$$

Finally, it is obvious that $\partial v_{j} / \partial a_{0}>0$, as $a_{0}$ is chosen optimally by the office holder, $n$, but $j \neq n$ does not bear the cost of the action. So, from this fact, (A-2) and (A-6), we conclude that $v_{j}^{\prime}(\gamma)>0, \gamma \leq \widetilde{g}_{0}$ so $j<n-1$ most prefers a cutoff at least $\widetilde{g}_{0}$, as required.

Proof of Proposition 5. It is sufficient to show that there does not exist a cutoff $\gamma \neq \widetilde{g}_{0}$ where all citizens are better off than at the equilibrium cutoff. Recall from Proposition $4, i \in V$ strictly prefer a cutoff $\gamma>\widetilde{g}_{0}$. So, it suffices to prove that $j=n$ strictly prefers a cutoff $\gamma<\widetilde{g}_{0}$.

The expected present value payoff of $n$ conditional on this cutoff $\gamma$, given that the officeholder 
optimizes his actions in both periods;

$$
\begin{aligned}
v_{n}(\gamma)= & \bar{\theta}+a_{0}(\gamma)+R-c\left(a_{0}(\gamma)\right)+\int_{\gamma}^{\infty} v_{c}\left(\pi_{1}\left(a_{0}(\gamma), g_{0}\right)\right) h\left(g_{0}, a_{0}(\gamma)\right) d g_{0} \\
& +H\left(\gamma, a_{0}(\gamma)\right) v_{c}\left(\pi_{0}\right)
\end{aligned}
$$

Note first that from (A-7) and the fact that $a_{0}(\gamma)$ maximizes (A-7):

$$
\begin{aligned}
v_{n}^{\prime}(\gamma) & =h\left(\gamma, a_{0}(\gamma)\right)\left[v_{c}\left(\pi_{0}\right)-v_{o}\left(\pi_{1}\left(a_{0}(\gamma), \gamma\right)\right)\right] \\
& <h\left(\gamma, a_{0}(\gamma)\right)\left[v_{c}\left(\pi_{0}\right)-v_{o}(0)\right] \\
& <0
\end{aligned}
$$

where the second line follows from the properties of $v_{o}, v_{c}$ given in Section 3.7, and the third from the assumption that $R>c\left(a^{*}\right)+\pi_{0}\left(\theta_{H}-\theta_{L}\right)$, which is equivalent to $v_{o}(0)>v_{c}\left(\pi_{0}\right)$ when $\mu=1$. So, from (A-8), $n$ prefers the lowest possible $\gamma=-\infty$ (i.e. no election).

\section{B. The Normal-Quadratic Case}

This specification is used in Example 1 of Section 5 and elsewhere in the paper. The cost of effort function is quadratic (specifically $c(a)=a^{2} / 2+d a$, with $d \geq 0$, so that $c^{\prime}(0) \geq 0$ ), and the error term $\varepsilon$ is Normally distributed with mean zero and variance $\sigma^{2}$. We can now prove that when the technology is additive (i.e. $\mu=1$ ), a unique equilibrium arises. In the appointment case, this is immediate as in this case there is no experimentation. For the democratic cases, when $\mu=1$, it is possible to calculate (details on request) that

$$
\begin{aligned}
\left.\frac{\partial E_{g_{0}}\left[w\left(\pi_{1}\right)\right]}{\partial a_{0}}\right|_{\mu=1}= & {\left[R-\delta-\frac{\left(a^{*}\left(\pi_{0}\right)\right)^{2}}{2}-d a^{*}\left(\pi_{0}\right)\right] } \\
& \left.\left.\times\left(\frac{\pi_{0}}{\sigma \sqrt{2 \pi}} \exp \left[-\frac{1}{8 \sigma^{2}}\left(\theta_{L}-\theta_{H}\right)\right)^{2}\right]+\frac{\left(1-\pi_{0}\right)}{\sigma \sqrt{2 \pi}} \exp \left[-\frac{1}{8 \sigma^{2}}\left(\theta_{H}-\theta_{L}\right)\right)^{2}\right]\right)
\end{aligned}
$$

which is decreasing in $a^{*}\left(\pi_{0}\right)$. On the other hand, the marginal cost of effort is upward sloping. Hence a unique equilibrium exists. The simulations reported in the paper are also based on this special case. Details are available on request.

\section{Derivations}

\section{Derivation of (15)}

(Adapted from the proof of Proposition 2 of Mirman and others, 1993). Before turning to the derivation of equation (15) itself, the following results are useful. First:

$$
\frac{d \pi_{1}\left(g_{0}, a_{0}\right)}{d g_{0}}=\frac{\pi_{0}\left(1-\pi_{0}\right)}{\left[\pi_{0} f_{H}+\left(1-\pi_{0}\right) f_{L}\right]^{2}}\left(f_{L} f_{H}^{\prime}-f_{H} f_{L}^{\prime}\right) \geq 0
$$


where $f_{H}=f\left(g_{0}-(1-\mu) \theta_{H} a_{0}-\mu\left(\theta_{H}+a_{0}\right)\right)$, and $f_{L}=$ $f\left(g_{0}-(1-\mu) \theta_{L} a_{0}-\mu\left(\theta_{L}+a_{0}\right)\right) .\left(f_{L} f_{H}^{\prime}-f_{H} f_{L}^{\prime}\right) \geq 0$ follows from the MLR property. Second:

$$
\begin{aligned}
\frac{d \pi_{1}\left(g_{0}, a_{0}\right)}{d a_{0}} & =-\left[\mu+(1-\mu) \theta_{H}\right] \frac{d \pi_{1}}{d g_{0}}-\frac{\pi_{0}\left(1-\pi_{0}\right)(1-\mu)\left(\theta_{H}-\theta_{L}\right)}{\left[\pi_{0} f_{H}+\left(1-\pi_{0}\right) f_{L}\right]^{2}} f_{H} f_{L}^{\prime} \\
& =-\left[\mu+(1-\mu) \theta_{L}\right] \frac{d \pi_{1}}{d g_{0}}-\frac{\pi_{0}\left(1-\pi_{0}\right)(1-\mu)\left(\theta_{H}-\theta_{L}\right)}{\left[\pi_{0} f_{H}+\left(1-\pi_{0}\right) f_{L}\right]^{2}} f_{L} f_{H}^{\prime}
\end{aligned}
$$

We can now evaluate (15). Notice that

$$
E_{g_{0}} v_{o}\left[\pi_{1}\left(g_{0}, a_{0}\right)\right]=\int_{-\infty}^{+\infty} v_{o}\left[\pi_{1}\left(g_{0}, a_{0}\right)\right] h\left(g_{0}, a_{0}\right) d g_{0}
$$

where $h\left(g_{0}, a_{0}\right)=\pi_{0} f_{H}+\left(1-\pi_{0}\right) f_{L}$. Thus, denoting $d E_{g_{0}} v_{o}\left[\pi_{1}\left(g_{0}, a_{0}\right)\right] / d a_{0}=\Gamma$, we have:

$$
\Gamma=\int v_{o}^{\prime} \frac{d \pi_{1}}{d a_{0}}\left[\pi_{0} f_{H}+\left(1-\pi_{0}\right) f_{L}\right] d g_{0}-\int v_{o}\left[\begin{array}{c}
\pi_{0}\left(\mu+(1-\mu) \theta_{H}\right) f_{H}^{\prime} \\
+\left(1-\pi_{0}\right)\left(\mu+(1-\mu) \theta_{H}\right) f_{L}^{\prime}
\end{array}\right] d g_{0}
$$

Integrating by parts the second term of (A-12) and then rearranging with the first term gives

$$
\begin{aligned}
\Gamma= & \int v_{o}^{\prime}\left(\frac{d \pi_{1}}{d a_{0}}+\left(\mu+(1-\mu) \theta_{H}\right) \frac{d \pi_{1}}{d g_{0}}\right) \pi_{0} f_{H} d g_{0} \\
& +\int v_{o}^{\prime}\left(\frac{d \pi_{1}}{d a_{0}}+\left(\mu+(1-\mu) \theta_{L}\right) \frac{d \pi_{1}}{d g_{0}}\right)\left(1-\pi_{0}\right) f_{L} d g_{0}
\end{aligned}
$$

Using (A-10) and (A-11), expression (A-13) becomes

$$
\begin{aligned}
\Gamma= & -\int v_{o}^{\prime} \frac{\pi_{0}\left(1-\pi_{0}\right)(1-\mu)}{\left[\pi_{0} f_{H}+\left(1-\pi_{0}\right) f_{L}\right]^{2}}\left(\theta^{H}-\theta^{L}\right) f_{H} f_{L}^{\prime} \pi_{0} f_{H} d g_{0} \\
& -\int v_{o}^{\prime} \frac{\pi_{0}\left(1-\pi_{0}\right)(1-\mu)}{\left[\pi_{0} f_{H}+\left(1-\pi_{0}\right) f_{L}\right]^{2}}\left(\theta^{H}-\theta^{L}\right) f_{H}^{\prime} f_{L}\left(1-\pi_{0}\right) f_{L} d g_{0}
\end{aligned}
$$

Because $\pi_{1}=\pi_{0} f_{H} /\left[\pi_{0} f_{H}+\left(1-\pi_{0}\right) f_{L}\right]$ and $\left(1-\pi_{1}\right)=\left(1-\pi_{0}\right) f_{L} /\left[\pi_{0} f_{H}+\left(1-\pi_{0}\right) f_{L}\right]$, equation (A-14) becomes

$$
\Gamma=-\left(\theta_{H}-\theta_{L}\right)\left\{\int v_{o}^{\prime} \pi_{1}^{2}\left(1-\pi_{0}\right)(1-\mu) f_{L}^{\prime} d g_{0}+\int v_{o}^{\prime}\left(1-\pi_{1}\right)^{2} \pi_{0}(1-\mu) f_{H}^{\prime} d g_{0}\right\}
$$

Using the fact that $\left(1-\pi_{1}\right)^{2}=\left(1-\pi_{1}\right)-\pi_{1}\left(1-\pi_{1}\right)$, we can rewrite (A-15) as

$$
\Gamma=-\left(\theta_{H}-\theta_{L}\right)\left\{\begin{array}{c}
\int v_{o}^{\prime}(1-\mu) \pi_{1}\left[\pi_{1}\left(1-\pi_{0}\right) f_{L}^{\prime}-\left(1-\pi_{1}\right) \pi_{0} f_{H}^{\prime}\right] d g_{0} \\
+\int v_{o}^{\prime}(1-\mu)\left(1-\pi_{1}\right) \pi_{0} f_{H}^{\prime} d g_{0}
\end{array}\right\}
$$

Rearranging the posterior belief $\pi_{1}$, we have $\pi_{1}\left[\pi_{0} f_{H}+\left(1-\pi_{0}\right) f_{L}\right]=\pi_{0} f_{H}$, which, after 
-28 -

APPENDIX I

differentiating with respect to $g_{0}$ gives (after rearranging)

$$
f_{L}^{\prime} \pi_{1}\left(1-\pi_{0}\right)-f_{H}^{\prime} \pi_{0}\left(1-\pi_{1}\right)=-\frac{d \pi_{1}}{d g_{0}}\left[\pi_{0} f_{H}+\left(1-\pi_{0}\right) f_{L}\right]
$$

Inserting (A-17) in (A-16) yields,

$$
\Gamma=\left(\theta_{H}-\theta_{L}\right)\left\{\begin{array}{c}
\int v_{o}^{\prime}(1-\mu) \pi_{1} \frac{d \pi_{1}}{d g_{0}} \pi_{0} f_{H} d g_{0}+\int v_{o}^{\prime}(1-\mu) \pi_{1} \frac{d \pi_{1}}{d g_{0}}\left(1-\pi_{0}\right) f_{L} d g_{0} \\
-\int v_{o}^{\prime}(1-\mu)\left(1-\pi_{1}\right) \pi_{0} f_{H}^{\prime} d g_{0}
\end{array}\right\}
$$

From the $\pi_{1}$ expression, we have $f_{L}\left(1-\pi_{0}\right) \pi_{1}=f_{H} \pi_{0}\left(1-\pi_{1}\right)$, so (A-18) becomes

$$
\Gamma=\left(\theta_{H}-\theta_{L}\right)\left\{\int v_{o}^{\prime}(1-\mu) \frac{d \pi_{1}}{d g_{0}} \pi_{0} f_{H} d g_{0}-\int v_{o}^{\prime}(1-\mu)\left(1-\pi_{1}\right) \pi_{0} f_{H}^{\prime} d g_{0}\right\}
$$

Now we integrate the second term in (A-19) by parts. This yields,

$$
\begin{aligned}
(1-\mu) \pi_{0} \int v_{o}^{\prime}\left(1-\pi_{1}\right) f_{H}^{\prime} d g_{0}= & -(1-\mu) \pi_{0} \int v_{o}^{\prime \prime}\left(1-\pi_{1}\right) \frac{d \pi_{1}}{d g_{0}} f_{H} d g_{0} \\
& +(1-\mu) \pi_{0} \int v_{o}^{\prime} \frac{d \pi_{1}}{d g_{0}} f_{H} d g_{0}
\end{aligned}
$$

Inserting (A-20) in (A-19) gives (15).

Derivation of equation (22)

The derivation is similar to that of equation (15). First, note that $E_{g_{0}}\left[w\left(\pi_{1}\left(g_{0}, a_{0}\right)\right)\right\}$ can be written

$$
\begin{aligned}
E_{g_{0}}\left[w\left(\pi_{1}\left(g_{0}, a_{0}\right)\right)\right] & =\left(v_{c}\left(\pi_{0}\right)-v_{o}\left(\pi_{0}\right)\right) H\left(\widetilde{g}_{0}, a_{0}\right)+\int_{\tilde{g}_{0}}^{+\infty}\left(v_{o}\left(\pi_{1}\left(g_{0}, a_{0}\right)\right)-v_{o}\left(\pi_{0}\right)\right) h\left(g_{0}, a_{0}\right) d g_{0} \\
& =\left[c\left(a^{*}\left(\pi_{0}\right)\right)-R\right] H\left(\widetilde{g}_{0}, a_{0}\right)+\int_{\tilde{g}_{0}}^{+\infty} \phi\left(\left(\pi_{1}\left(g_{0}, a_{0}\right)\right) h\left(g_{0}, a_{0}\right) d g_{0}\right.
\end{aligned}
$$

where $\phi\left(\pi_{1}\left(g_{0}, a_{0}\right)\right)=v_{o}\left(\pi_{1}\left(g_{0}, a_{0}\right)\right)-v_{o}\left(\pi_{0}\right)$, so $\phi\left(\pi_{1}\left(\tilde{g}_{0}, a_{0}^{*}\right)\right)=0, \phi^{\prime}=v_{o}^{\prime}$. So,

$$
\begin{aligned}
\Gamma \equiv & \frac{d E_{g_{0}}\left[w^{*}\left(\pi_{1}\left(g_{0}, a_{0}\right)\right)\right]}{d a_{0}}=\left(v_{c}\left(\pi_{0}\right)-v_{o}\left(\pi_{0}\right)\right)\left(-\frac{\partial H\left(\widetilde{g}_{0}, a_{0}\right)}{\partial a_{0}}\right) \\
& +\int_{g_{0}}^{+\infty} \phi^{\prime} \frac{d \pi_{1}}{d a_{0}}\left[\pi_{0} f_{H}+\left(1-\pi_{0}\right) f_{L}\right] d g_{0} \\
& -\int_{g_{0}}^{+\infty} \phi\left[\pi_{0}\left(\mu+(1-\mu) \theta_{H}\right) f_{H}^{\prime}+\left(1-\pi_{0}\right)\left(\mu+(1-\mu) \theta_{L}\right) f_{L}^{\prime}\right] d g_{0}
\end{aligned}
$$


Integrating by parts the third term of (A-21) and then rearranging with the first two terms gives

$$
\begin{aligned}
\Gamma= & \int_{g_{0}}^{+\infty} \phi^{\prime}\left(\frac{d \pi_{1}}{d a_{0}}+\left(\mu+(1-\mu) \theta_{H}\right) \frac{d \pi_{1}}{d g_{0}}\right) \pi_{0} f_{H} d g_{0} \\
& +\int_{g_{0}}^{+\infty} \phi^{\prime}\left(\frac{d \pi_{1}}{d a_{0}}+\left(\mu+(1-\mu) \theta_{L}\right) \frac{d \pi_{1}}{d g_{0}}\right)\left(1-\pi_{0}\right) f_{L} d g_{0} \\
& +\left[R-c\left(a^{*}\left(\pi_{0}\right)\right)\right]\left(-\frac{\partial H\left(\widetilde{g}_{0}, a_{0}\right)}{\partial a_{0}}\right)
\end{aligned}
$$

After using similar manipulations as for the derivation of equation (15), we obtain

$$
\begin{aligned}
\Gamma= & \left(\theta_{H}-\theta_{L}\right)\left\{\int_{g_{0}}^{+\infty} \phi^{\prime}(1-\mu) \frac{d \pi_{1}}{d g_{0}} \pi_{0} f_{H} d g_{0}-\int_{g_{0}}^{+\infty} \phi^{\prime}(1-\mu)\left(1-\pi_{1}\right) \pi_{0} f_{H}^{\prime} d g_{0}\right\} \\
& +\left[R-c\left(a^{*}\left(\pi_{0}\right)\right)\right]\left(-\frac{\partial H\left(\widetilde{g}_{0}, a_{0}\right)}{\partial a_{0}}\right)
\end{aligned}
$$

Now we integrate the second term in (A-23) by parts. This yields,

$$
\begin{aligned}
(1-\mu) \pi_{0} \int_{g_{0}}^{+\infty} \phi^{\prime}\left(1-\pi_{1}\right) f_{H}^{\prime} d g_{0}= & -(1-\mu) \pi_{0} \int_{g_{0}}^{+\infty}\left(\phi^{\prime \prime} \frac{d \pi_{1}}{d g_{0}}\right)\left(1-\pi_{1}\right) f_{H} d g_{0} \quad \text { (A-24) } \\
& +(1-\mu) \pi_{0} \int_{g_{0}}^{+\infty} \phi^{\prime} \frac{d \pi_{1}}{d g_{0}} f_{H} d g_{0} \\
& -\frac{d \phi\left(\pi_{1}\left(\widetilde{g}_{0}, a_{0}\right)\right)}{d \pi_{1}}\left(1-\pi_{1}\left(\widetilde{g}_{0}, a_{0}\right)\right) \pi_{0}(1-\mu) f_{H}\left(\widetilde{g}_{0}\right)
\end{aligned}
$$

Inserting (A-24) in (A-23), and using $\phi^{\prime}=v_{0}^{\prime}$, and finally evaluating at $a_{0}=a_{0}^{*}$ (and recalling $\left.\pi_{1}\left(\widetilde{g}_{0}, a_{0}\right)=\pi_{0}\right)$ gives equation (22). 


\section{References}

Austen-Smith, D., and J. Banks, 1989, "Electoral Accountability and Incumbency," in Models of Strategic Choice in Politics, ed. by P. Ordershook (Ann Arbor, Michigan: University of Michigan Press).

Banks, J.S., and R.K. Sundaram, 1993, "Adverse Selection and Moral Hazard in a Repeated Elections Model," in Political Economy: Institutions, Information Competition, and Representation, ed. by W. Barnett and others (Cambridge, England: Cambridge University Press).

__ 1998, "Optimal Retention in Agency Problems," Journal of Economic Theory, Vol. 82 (October), pp. 293-323.

Barro, R., 1973, "The Control of Politicians: An Economic Model," Public Choice, Vol. 14 (Spring), pp. 19-42.

Besley, T., and A. Case, 1995, "Does Electoral Accountability Affect Economic Policy Choices? Evidence From Gubernatorial Term Limits," Quarterly Journal of Economics, Vol. 110 (August), pp. 769-98.

_- and S. Coate, 1998, "Sources of Inefficiency in a Representative Democracy: A Dynamic Analysis," American Economic Review, Vol. 88 (March), pp. 139-56.

- 1997, "An Economic Model of Representative Democracy," Quarterly Journal of Economics, Vol. 112 (February), pp. 85-114.

Besley, T., and M. Smart, 2001, "Does Tax Competition Raise Voter Welfare?" (unpublished; London School of Economics).

Biglaiser, G., and C. Mezzetti, 1997, "Politicians' Decision Making With Re-election Concerns," Journal of Public Economics, Vol. 66 (December), pp. 425-47.

Coate. S., and S. Morris, 1995, "On the Form of Transfers to Special Interests," Journal of Political Economy, Vol. 103 (December), pp. 1210-35.

Cox, G.W., 1997, Making Votes Count (Cambridge, England: Cambridge University Press).

Datta, M., L.J. Mirman, and E.E. Schlee, 2002, "Optimal Experimentation In Signal-Dependent Decision Problems," International Economic Review, Vol. 43 (May), pp. 577-607.

Dewatripont, M, I. Jewitt, and J. Tirole, 1999, "The Economics of Career Concerns, Part II: Application to Missions and Accountability of Government Agencies," Review of Economic Studies, Vol. 66 (January), pp. 199-217.

Dhillon, A., and B. Lockwood, 2000, "When are Plurality Rule Voting Games Dominance-Solvable?" forthcoming in Games and Economic Behaviour.

Ferejohn, J., 1986, "Incumbent Performance and Electoral Control," Public Choice, Vol. 50 (1-3), pp. 5-26.

Gibbons, R., and M. Waldman, 1999, "Careers in Organizations: Theory and Evidence," in O. Ashenfelter and D. Card, Handbook of Labor Economics, Ch. 36, pp. 2373-437. 
Green, J., and N. Stokey, 1983, "Tournaments and Contracts," Journal of Political Economy, Vol. 91 (June), pp. 349-64.

Grossman, S.J., R.E. Kihlstrom, and L.J. Mirman, 1977, "A Bayesian Approach to the Production of Information and Learning by Doing," Review of Economic Studies, Vol. 44 (October), pp. $533-47$.

Holmström, B., 1999, "Managerial Incentive Problems: A Dynamic Perspective," Review of Economic Studies, Vol. 66 (January), pp. 169-82. Originally, 1982, in Essays in Economics and Management in Honor of Lars Wahlbeck (Helsinki: Swedish School of Economics).

_ , and P. Milgrom, 1991, "Multitask Principal-Agent Analyses: Incentive Contracts, Asset Ownership, and Job Design," Journal of Law, Economic and Organizations, Vol. 7 (Special Issue), pp. 24-51.

Keller, G., and S. Rady, 1999, "Optimal Experimentation in a Changing Environment," Review of Economic Studies, Vol. 66 (July), pp. 475-507.

Lazear, E.P., and S. Rosen, 1981, "Rank-Order Tournaments as Optimum Labor Contracts," Journal of Political Economy, Vol. 89 (October), pp. 841-64.

Le Borgne, E., and B. Lockwood, 2000, "Do Elections Always Motivate Incumbents?," University of Warwick, Department of Economics, Working Paper Series No. 580.

_ 2002, "Candidate Entry, Screening, and Political Bugdet Cycle," IMF Working Paper 02/48 (Washington: International Monetary Fund).

Milgrom, P., 1981, "Good News and Bad News: Representation Theorems and Applications," Bell Journal of Economics, Vol. 12 (Autumn), pp. 380-91.

Mirman, L.J, L. Samuelson, and A. Urbano, 1993, "Monopoly Experimentation," International Economic Review, Vol. 34 (August), pp. 549-63.

Persson, T., and G. Tabellini, 2000, Political Economics: Explaining Economic Policy (MIT Press, Cambridge, MA).

Prendergast, C., 1999, "The Provision of Incentives in Firms," Journal of Economic Literature, Vol. 37 (March), pp. 7-63.

Prescott, E.C., 1972, "The Multi-Period Control Problem Under Uncertainty," Econometrica, Vol. 40 (November), pp. 1043-58.

Rogoff, K., 1990, "Equilibrium Political Budget Cycles," American Economic Review, Vol. 80 (March), pp. 21-36.

— Siudies, Vol. 55 (January), pp. 1-16.

Wittman, D., 1989, "Why Democracies Produce Efficient Results," Journal of Political Economy, Vol. 97 (December), pp. 1395-426. 